\title{
El uso inadecuado de aceites de frituras genera malonaldehído, sustancia tóxica para la salud
}

The improper use of deep-frying oils generates malonaldehyde, a toxic substance for health

\author{
O uso indevido de óleos de fritura gera malonaldeído, \\ uma substância tóxica para a saúde
}

\section{Nayibe Bonilla Mosquera ${ }^{1}$ María Fernanda Pérez Garzón² Juan Carlos Millán Estupiñán ${ }^{3}$}

Recibido: 12 de agosto de 2020 Aprobado: 29 de octubre de 2020 Publicado: 12 de enero de 2021

Cómo citar este artículo: Nayibe Bonilla, María Fernanda Pérez, Juan Carlos Millán. El uso inadecuado de aceites de frituras genera malonaldehído, sustancia tóxica para la salud.

Artículo de investigación. https://doi.org/10.16925/2357-5891.2021.01.01

1 Estudiante de Maestría en Educación Ambiental y Desarrollo Sostenible. Docente Universidad Santiago de Cali.

Correo electrónico: nayibebonilla00@yahoo.com

2 Estudiante de Maestría en Educación Ambiental y Desarrollo Sostenible. Docente Universidad Santiago de Cali.

Correo electrónico: neurotransmisor17@gmail.com

3 Director de trabajo de grado. Docente de posgrados en Salud. Docente de Salud Pública de la Universidad Santiago de Cali.

Correo electrónico: jcmillan@usc.edu.co 


\section{Resumen}

Tema y alcance: el propósito de este estudio fue analizar el contenido de aldehídos, específicamente malonaldehído, presente en aceites de frituras para la preparación de alimentos en la Universidad Santiago de Cali, sus efectos en la salud durante 2016-2017 y la vulneración del derecho a un ambiente sano.

Características: estudio observacional, descriptivo de corte transversal. Se realizó análisis univariado y bivariado. Se utilizó una hoja de cálculo Epi Info versión 7.0. Se entrevistó al personal que labora en las cafeterías de una institución de educación superior y se estudiaron las normas constitucionales.

Hallazgos: este estudio encontró que existe una ligera tendencia a obtener mayores valores en las mediciones del pH para el caso de los aceites nuevos empleados en cada uno de los establecimientos, pero en las mediciones de los aceites reusados los $\mathrm{pH}$ fueron bajos. También, es importante destacar que en ningún caso las mediciones de $\mathrm{pH}$ para los aceites nuevos fueron menores a los valores para los aceites usados. Al analizar el bivariado entre el valor del promedio de la muestra y la prueba TBA, se encontró que a mayores valores de promedio, los valores de la prueba de TBA aumentaron, con un coeficiente de correlación de rangos de Spearman de 1 (correlación perfecta).

Conclusión: los parámetros evaluados de $\mathrm{pH}$, color, temperatura y formación de TBA permitieron confirmar el cambio en las cualidades de los aceites analizados y la presencia de malonaldehído en las muestras recolectadas en las cafeterías y en las réplicas obtenidas en el laboratorio, lo que genera expectativas frente a la salud de la población y requiere de toma de decisiones por parte de la institución.

Palabras clave: Corte Constitucional, derecho al medio ambiente sano, malonaldehído, pH, prueba de TBA.

\section{Abstract}

Subject and scope: The aim of this paper was to analyze aldehyde content, specifically malonaldehyde, present in deep-frying oils used in food preparation in Universidad Santiago de Cali, its health effects during 2016-2017 and the transgression of the right to a healthy environment.

Characteristics: An observational, descriptive, and cross-sectional study. Univariate and bivariate analysis was conducted. An Epi Info version 7.0 spreadsheet was used. The personnel working in the cafeterias of a higher education institution were interviewed and the constitutional norms were studied.

Findings: The study found that there is a slight tendency to obtain higher values in the $\mathrm{pH}$ measurements in the case of the new oils used in each of the establishments, but in the measurements of the reused oils, the $\mathrm{pH}$ were lower. Also, it is important to note that in any case the $\mathrm{pH}$ measurements for new oils were lower than the values for used oils. When conducting the bivariate analysis between the sample mean value and the tba test, it was found that the higher the mean values, the tba test values increased, with a Spearman correlation coefficient of 1 (perfect correlation).

Conclusion: The evaluated parameters of $\mathrm{pH}$, color, temperature and tba formation allowed to confirm the change in the qualities of the analyzed oils and the presence of malonaldehyde in the samples collected in the cafeterias and, also, in the replicas obtained in the laboratory, which generates expectations regarding the health of the population and requires decision-making by the institution.

Keywords: Constitutional Court; Right to a Healthy Environment; Malonaldehyde; pH; tba test.

\section{Resumo}

Assunto e escopo: 0 objetivo deste artigo foi analisar o teor de aldeído, especificamente o malonaldeído, presente em óleos de fritura usados na preparação de alimentos na Universidade de Santiago de Cali, seus efeitos na saúde durante 2016-2017 e a transgressão do direito a uma saúde ambiente. 
Características: Estudo observacional, descritivo e transversal. Foi realizada análise univariada e bivariada. Foi utilizada uma planilha Epi Info versão 7.0. Foram entrevistados os funcionários que trabalham nos refeitórios de uma instituição de ensino superior e estudadas as normas constitucionais.

Resultados: 0 estudo constatou que existe uma ligeira tendência para obtenção de valores superiores nas medições de $\mathrm{pH}$ no caso dos óleos novos utilizados em cada um dos estabelecimentos, mas nas medições dos óleos reutilizados os $\mathrm{pH}$ foram inferiores. Além disso, é importante notar que em qualquer caso, as medições de $\mathrm{pH}$ para óleos novos foram inferiores aos valores para óleos usados. Ao realizar a análise bivariada entre o valor médio da amostra e o teste de TBA, verificou-se que quanto maiores os valores médios, aumentaram os valores do teste de TBA, com coeficiente de correlação de Spearman igual a 1 (correlação perfeita).

Conclusão: Os parâmetros avaliados de $\mathrm{pH}$, cor, temperatura e formação de TBA permitiram confirmar a mudança nas qualidades dos óleos analisados e a presença de malonaldeído nas amostras coletadas nos refeitórios e, também, nas réplicas obtidas em laboratório, o que gera expectativas em relação à saúde da população e requer tomada de decisão por parte da instituição.

Palavras-chave: Tribunal Constitucional; Direito a um Ambiente Saudável; Malonaldeído; pH; Teste TBA.

\section{INTRODUCCIÓN}

La actual crisis medioambiental que afecta gravemente a todo el mundo es consecuencia de las crecientes presiones antropogénicas sobre la biosfera planetaria. En este sentido, es extremadamente importante determinar los cambios posibles y más probables del volumen de la población del planeta en el futuro, así como la evolución prevista de la cantidad de "contaminantes ambientales" producidos por una persona.

La situación en los países en vías de desarrollo se agrava por el hecho de que los países industrializados intentan ubicar allí sus complejos de producción contaminante, debido en parte a que la legislación ambiental no es tan estricta en estos países, lo que implica menores costes ambientales.

Las ciudades peligrosas para el ambiente' se caracterizan por una elevada incidencia de las enfermedades, muchas de las cuales están directamente relacionadas con las malas condiciones ambientales: "Las enfermedades respiratorias graves, la tuberculosis, los parásitos intestinales y otras enfermedades asociadas a las malas condiciones sanitarias y al consumo de agua contaminada suelen ser endémicas; constituyen una de las principales causas de enfermedad y mortandad especialmente en la infancia".

1 Denier Palacios Mena y Maryuri Moreno Rodallega. Medidas de mitigación y corrección que utiliza el Estado para subsanar los daños producidos por los entables mineros en el barrio El Oasis del municipio de Certegui, departamento de Chocó. DIXI 30. 2019. Pág. 1-28. Disponible en https://repository.ucc.edu.co/handle/20.500.12494/17025 
La protección del medio ambiente, que se desprende principalmente de los artículos 8, 79 y 95 de la Constitución Política, es un objetivo del Estado social de derecho que se inscribe en la llamada "Constitución Ecológica" y contempla la protección de los animales como un deber para todos los individuos, la sociedad y el Estado. Así pues, tal interés superior incluye la protección de la fauna ante el padecimiento, el maltrato y la crueldad con algunas excepciones, al igual que la protección de su progresiva desaparición, lo cual refleja un contenido de moral política y conciencia de la responsabilidad que deben tener los seres humanos respecto a otros seres sintientes ${ }^{2}$.

Una de las herramientas que ordena la Constitución para la concreción de la protección del medio ambiente, específicamente a partir de sus artículos 67 y 79 , es el fomento a la educación, lo cual resulta determinante para consolidar políticas públicas que requieren de la participación ciudadana y, en general, como instrumento para alcanzar los fines del Estado, en particular la protección de los animales como parte del medio ambiente.

A continuación se presentan, a manera de resumen, algunas sentencias sobre la protección del medio ambiente en Colombia:

\section{Sentencias de constitucionalidad}

- Sentencia C-035/16 M.P. Gloria Ortiz Delgado. Autonomía territorial, minería, ecosistemas estratégicos y páramos.

- Sentencia C-123/14 M.P. Alberto Rojas Ríos. Vulneración de la competencia de los Concejos para regular los usos del suelo en el territorio del municipio o distrito y por desconocimiento de la protección que la Constitución obliga a brindar al derecho a un ambiente sano.

- Sentencia C-036/14 M.P. Luis Ernesto Vargas Silva. Enmienda al convenio de Basilea sobre el control de movimientos transfronterizos de desechos peligrosos y su eliminación.

- Sentencia C-094/15 M.P. Luis Ernesto Vargas Silva. Demanda de inconstitucionalidad contra el Decreto 1111 de 1952, por el cual se provee la conservación y mejor aprovechamiento de las aguas del lago de Tota y se reconoce el carácter de utilidad pública a unas obras.

- Sentencia C-371/14 M.G. Jorge Ignacio Pretelt Chaljub. Demanda de inconstitucionalidad contra los artículos 79, 80, 81, 82, 83 y 84 de la Ley

2 Corte Constitucional de Colombia. SENTENCIA C-032 de 2019. (M.P. Gloria Stella Ortiz Delgado; enero 30 de 2019). Disponible en https://www.corteconstitucional.gov.co/relatoria/2019/C-032-19.htm 
160 de 1994, por la cual se crea el Sistema Nacional de Reforma Agraria y Desarrollo Rural Campesino, se establece un subsidio para la adquisición de tierras, se reforma el Instituto Colombiano de la Reforma Agraria y se dictan otras disposiciones.

- Sentencia C-943/12 M.P. María Victoria Calle. Acción de inconstitucionalidad contra el Decreto 3573 del 27 de septiembre de 2011, "por el cual se crea la Autoridad Nacional de Licencias Ambientales (ANLA) y se dictan otras disposiciones".

- Sentencia C-326/12 M.P. Humberto Sierra Porto. Competencia de autoridad indígena sobre asuntos ambientales.

- Sentencia C-276/11 M.P. Mauricio González Cuervo. "Control de Constitucionalidad del Decreto Legislativo 141 de 2011".

- Sentencia C-216/11 M.P. Juan Carlos Henao Pérez. "Control de Constitucionalidad del Decreto Legislativo 020 de 2011 declaratorio del Estado de Emergencia Económica, Social y Ecológica, por segunda vez".

- Sentencia C-598/10 M.P. Mauricio González Cuervo. "Áreas protegidas de Parques Naturales de carácter regional".

- Sentencia C-189/06 M.P. Rodrigo Escobar Gil. "Derecho de propiedad y Sistema de Parques Nacionales Naturales".

- Sentencia C-1048/04 M.P. Jaime Araujo Rentería. "Naturaleza jurídica de las Corporaciones Autónomas Regionales (CAR)".

- Sentencia C-620/03 M.P. Marco Gerardo Monroy Cabra. "Explotación de recursos naturales en territorio indígena: zona salinífera de Manaure."

- Sentencia SU-383/03 M.P. Álvaro Tafur Galvis. "Derechos fundamentales de la Comunidad Indígena de la Amazonía".

- Sentencia C-251/03. M.P. Manuel José Cepeda Espinosa. "Explotación de recursos naturales no renovables: propiedad, regalías, derechos y compensaciones".

- Sentencia C-891/02. M.P. Jaime Araujo Rentería. "Código de Minas: Consulta previa en exploración y explotación de recursos en zona minera indígena y mixta."

- Sentencia C-710/01. M.P. Jaime Córdoba Triviño. "Debido proceso administrativo para imponer las sanciones previstas en la Ley 99 de 1993".

- Sentencia C-431/00. M.P. Vladimiro Naranjo Mesa. "Ordenamiento Territorial y protección ambiental".

- Sentencia C-215/99. M.P. Martha Victoria Sáchica de Moncaleano. "Acción Popular". 
- Sentencia C-193/98 M.P. Alejandro Martínez Caballero y Hernando Herrera Vergara. "Acción de cumplimiento".

- Sentencia C-126/98 M.P. Alejandro Martínez Caballero. "Demanda de inconstitucionalidad contra el Código Nacional de Recursos Naturales Renovables y de Protección al Medio Ambiente (Decreto-Ley 2811 de 1974)".

- Sentencia C-243/97 M.P. Fabio Morón Díaz. "Autoridades competentes para la expedición de normas ambientales".

- Sentencia C-221/97 M.P. Alejandro Martínez Caballero. "Deber de imponer regalías sobre la explotación de los recursos naturales no renovables e imposibilidad de gravar tal explotación".

- Sentencia SU-039/97 M.P. Antonio Barrera Carbonell. "Explotación de recursos naturales en territorio indígena (Caso U'wa)".

- Sentencia C-535/96 M.P. Antonio Barrera Carbonell. "Autonomía de las entidades territoriales y protección del medio ambiente sano: contaminación visual, protección del paisaje y defensa del patrimonio ecológico local".

- Sentencia C-534/96 M.P. Fabio Morón Díaz. "Competencias en materia ambiental: autoridades ambientales y entidades territoriales".

- Sentencia C-495/96 M.P. Fabio Morón Díaz. "Constitucionalidad de las tasas retributivas y compensatorias en materia ambiental".

- Sentencia C-359/96M.P. Antonio Barrera Carbonell. "Convenio Internacional de Constitución de un Fondo Internacional de Indemnización de Daños Causados por la Contaminación de Hidrocarburos".

- Sentencia C-262/96 M.P. Eduardo Cifuentes Muñoz. "Convenio para la protección de obtenciones vegetales".

- $\quad$ Sentencia C-137/96 M.P. Eduardo Cifuentes Muñoz. "Estatuto del Centro Internacional de Ingeniería Genética y Biotecnología".

- Sentencia C-305/95 M.P. Antonio Barrera Carbonell. "Porcentaje ambiental para las Corporaciones Autónomas Regionales (CAR)".

- Sentencia C-389/94 M.P. Antonio Barrera Carbonell. "Sentido y alcance de la extinción del dominio, la expropiación y la función social de la propiedad".

\section{Sentencias de tutela}

- Sentencia T-362/14 M.P. Jorge Ignacio Pretelt Chaljub. Protección de los derechos fundamentales al agua potable, a la salud y a la vivienda digna. 
- Sentencia T-204/14 M.P. Alberto Rojas Ríos. Derecho al trabajo y vida digna versus recursos naturales y ambiente sano.

- Auto n0 073/14 M.P. Luis Ernesto Vargas Silva. Medidas de prevención, protección y atención de las comunidades afrodescendientes de la región pacífica del departamento de Nariño, afectadas y/o en riesgo de ser perjudicadas por los fenómenos de desplazamiento forzado interno, confinamiento y resistencia.

- Sentencia de Tutela 462A/14 M.P. Jorge Ignacio Pretelt Chaljub. Falta de consulta previa antes de la construcción de la represa Salvajina y por el presunto incumplimiento de los acuerdos consignados en el "Acta 86", suscrita por el Gobierno nacional, incumplimiento que se alega haber sido agravado por el abandono estatal en el que alegan se encuentran las comunidades indígenas.

- Sentencia T-154/13 M.P. Nilson Pinilla Pinilla. Contaminación por minería de carbón en el departamento del Cesar.

- Sentencia T-1077/12 M.P. Jorge Ignacio Pretelt. Contaminación electromagnética.

- Sentencia T-348/12 M.P. Jorge Ignacio Pretelt. Sobre participación de comunidades afectadas por megaproyectos y soberanía alimentaria.

- Sentencia T-774/04 M.P. Manuel José Cepeda. Constitución Ecológica, biopesticida, algodón.

- Sentencia T-652/98 M.P. Carlos Gaviria Díaz. "Pueblo Embera y Urrá".

- Sentencia T-257/96 M.P. Antonio Barrera Carbonell. "Protección materia ambiental".

- $\quad$ Sentencia T-574/96 M.P. Alejandro Martínez Caballero. "Tutela en materia ambiental."

- Sentencia T-254/93 M.P. Antonio Barrera Carbonell. "Propal-Valle".

- Sentencia T-444/93 M.P. Antonio Barrera Carbonell. "Prevalencia tutela sobre acciones populares cuando se amenaza o vulnera un derecho fundamental, caso Canteras".

- $\quad$ Sentencia T-231/93 M.P. Alejandro Martínez Caballero. "Canal 'Bogotá' de cúcuta.

- $\quad$ Sentencia T-411/92 M.P. Alejandro Martínez Caballero. "Derecho al trabajo y vulneración ambiental."

- $\quad$ Sentencia T-528/92 M.P. Fabio Morón Díaz. "Protección ambiental por vía de tutela." 
- Sentencia T-437/92 M.P. José Gregorio Hernández Galindo. "El ambiente sano como derecho colectivo tutelable."

- Sentencia T-415/92 M.P. Ciro Angarita Barón. "Derechos colectivos, derechos fundamentales y derecho al ambiente sano (Bugalagrande, planta de asfalto)."

\section{Corte Suprema de Justicia Consejo de Estado}

- Sentencia 11001-03-06-000-2014-00248-00(2233), Sala de Consulta, 11 de diciembre de 2014. M.P. William Zambrano Cetina. Protección del Medio Ambiente.

- Sala de lo Contencioso Administrativo Sección Primera, Bogotá, 28 de marzo de 2014. M.P. Marco Antonio Velilla. Acción Popular. Derecho al goce de un ambiente sano.

- Sentencia, Sala de lo Contencioso Administrativo, Sección Primera, 24 de noviembre de 2011. "Ordena recuperar áreas invadidas del archipiélago Nuestra Señora del Rosario (Islas del Rosario)".

- Sentencia, Sala de lo Contencioso Administrativo, Sección Primera, 2 de marzo de 2006. "Facultad de la CAR para emitir licencias ambientales".

- Concepto, Sala de Consulta y Servicio Civil, 23 de noviembre de 2005. "Viabilidad de los transgénicos en Colombia".

- Concepto, Sala de Consulta y Servicio Civil, 29 de septiembre de 2005. "Bienes de propiedad privada y patrimonial de entidades públicas".

- Sentencia, Sala de Contencioso Administrativo, Sección Primera, 30 de octubre de 2003. "Licencias ambientales y OT".

- Concepto, Sala de Consulta y Servicio Civil, 16 de noviembre de 2000. "Distritos de Manejo Integrado de los Recursos Naturales Renovables, DMI".

La educación ambiental es un proceso que transcurre a la par con la formación permanente del individuo, y proporciona información, conocimientos y hábitos basados en las normas y valores que durante la vida adulta se consideren esenciales para el desenvolvimiento adecuado en la comunidad. A su vez, constituye el pilar de atención y respeto que se adquiere por la vida de los seres vivos y todos los recursos naturales, siendo esto un instrumento de mejor convivencia y salud para la sociedad. 
Es por ello que nace la inquietud de ahondar en la relación de la educación ambiental y el cuidado de la salud desde el punto de vista de una sana alimentación.

La alimentación de los seres humanos es un requerimiento de vital importancia para la formación y el desarrollo adecuado de todas las funciones corporales. Sin embargo, hoy existen diferentes formas de alimentarse, precisamente por la variedad de productos alimenticios que se ofrecen para satisfacer las necesidades del consumidor. De allí que los individuos, dadas las múltiples ocupaciones en las que hoy deben desenvolverse y los costos en los que deben incurrir para alimentarse, consuman comidas que pueden no ser nutritivas y solo llegar satisfacer una necesidad 3 .

En la actualidad, debido a la situación económica que padecen miles de colombianos, las personas buscan ganarse la vida con negocios que puedan generarles unos ingresos seguros y que a su vez les permitan tener una mejor calidad de vida. Uno de estos negocios es la producción de comida a bajo costo, cuya preparación requiere disminuir los costos para ofrecer un producto de calidad apropiada pero también a buen precio; es decir que la gente lo pueda comprar y se venda en el día toda la producción generada. A esto se le suma la costumbre colombiana ingerir toda clase de frituras, por su practicidad en la preparación y porque son muy aceptados en la sociedad. Además, está la ausencia de educación ambiental en las comunidades frente a la sana alimentación en todos los contextos ${ }^{4}$.

En las instituciones educativas ${ }^{5}$, en razón a las largas jornadas de estudio y trabajo se deben prestar los servicios de venta y distribución de alimentos en los restaurantes. Son estos los espacios donde se consumen alimentos que son preparados masivamente y a bajos costos, por tanto los insumos para la preparación deben tener precios adecuados y en el caso de los aceites para frituras suelen reutilizarlos al máximo ${ }^{6}$. Esto sucede porque en este tipo de instituciones no se realizan, en muchos casos, los estudios necesarios y el seguimiento para establecer la calidad de los insumos utilizados ni de los productos alimenticios ofrecidos. En este contexto, se debe tener en cuenta que el expendio de alimentos fritos y el uso de aceites recalentados

3 Corte Constitucional de Colombia. SENTENCIA T-029 de 2014. (M.P. Jorge Ignacio Pretelt Chaljub; enero 27 de 2014). Disponible en https://www.corteconstitucional.gov. co/relatoria/2014/T-029-14.htm

4 Francisco Javier Rivera Olarte. Breve estudio descriptivo del fenómeno ambiental en sus dos dimensiones: daño ambiental y daño ecológico. DIXI 25. 2017. Pág. 83-104. Disponible en https://dialnet.unirioja.es/servlet/articulo?codigo $=6794852$

5 Fernelly Varón-Martínez. El fenómeno de la deserción escolar en un contexto local: estudio de la política municipal. DIXI 26. Agosto de 2017. Disponible en https://doi. org/10.16925/di.v19i26.1953

6 Corte Constitucional de Colombia. SENTENCIA T-260 de 2019. (M.P. Antonio José Lizarazo Ocampo; junio 6 de 2019). Disponible en https://www.corteconstitucional.gov. co/relatoria/2019/T-260-19.htm 
son fuente de grasas trans en la dieta y de otras sustancias tóxicas para la salud como los aldehídos. Los problemas relacionados con la calidad de los alimentos son numerosos. Si esto es así, el sentido común sugiere que es importante definir los mecanismos legales y fortalecer las entidades que controlan la calidad de los alimentos, de acuerdo con Puente?

Según Vega ${ }^{8}$, el tipo de aceite empleado y el uso que se le dé pueden hacer que se altere. Las sustancias tóxicas generadas en el proceso de degradación pasan al alimento frito que absorbe parte del aceite utilizado en el proceso de fritura. Aprender las normas básicas de una fritura saludable es esencial para alargar la vida útil del aceite y disminuir la formación de compuestos tóxicos para la salud.

El Proyecto de Ley 08 de 2016, Cámara de Representantes, propone "establecer las condiciones de manejo, transporte, transformación y/o disposición final segura de los aceites lubricantes usados, de los aceites industriales usados y de los aceites de fritura usados en el territorio nacional", y prohibir "la combustión de los mismos o su reutilización parcial o total sin tratamiento de transformación".

En cuanto a los aceites usados en frituras, la mayoría de agentes generadores vierten esas sustancias a los sistemas de alcantarillado. En el mejor de los casos, las aguas contaminadas con esos desechos son tratadas por las plantas depuradoras de agua, lo cual genera un aumento elevado de los costos al ser eliminados mediante métodos físicos o químicos, que generan otro foco de contaminación, pues las concentraciones de grasa deben ser incineradas.

En el peor de los casos, las aguas contaminadas con aceite usado de frituras no son tratadas, y van a dar directamente a fuentes de aguas como ríos o lagos. Un litro de aceite puede contaminar mil litros de agua. El aceite forma una película superficial en el agua, lo que altera el intercambio de oxígeno y afecta a la fauna y la flora de los ecosistemas donde este desecho es vertido. Adicional a esto, las aguas contaminadas con aceite usado de fritura es el caldo perfecto para la multiplicación de agentes patógenos, lo que afecta negativamente la salud de los pobladores circundantes.

La Organización Mundial de la Salud (OMS) certifica que un litro de residuo de aceite vegetal de fritura usado contamina el consumo de agua de una persona durante 18 meses. En la actualidad, se están vertiendo solo en la ciudad de Bogotá alrededor de 25000 toneladas anuales de residuos de aceites de fritura usados; y al utilizar reiteradamente los aceites vegetales de fritura se generan elementos cancerígenos. Esta contaminación se puede evitar con el reciclaje, una práctica por la que avoca

7 Jairo Puentes Brugés. VEnENOS EN EL HOgar. Ediciones Usta. (2006).

8 Alberto Vega Turizo. GUÍA PARA LA ELABORACIÓN DE ACEITES COMESTIBLES, CARACTERIZACIÓN Y PROCESAMIENTO DE NUECES. Convenio Andrés Bello. (2004). 
el mencionado proyecto de ley. El reciclaje de aceite de fritura usado tiene muchas posibilidades y beneficios, pues industrias tan diversas como la química, la cosmética o la farmacéutica se aprovechan de este residuo para elaborar abonos, barnices, cera, cremas, detergentes, jabones, lubricantes, pinturas, velas, etc.

En cuanto a los aceites lubricantes e industriales usados o contaminados, de los que el proyecto de ley también se ocupa, son peligrosos debido a su baja biodegradabilidad, alta toxicidad, su degradación química en químicos aún más contaminantes, y la acumulación en seres vivos y generación de gases peligrosos. El principal método de eliminación usado por los agentes generadores de los aceites lubricantes e industriales usados o contaminados es la incineración. Sin embargo, la incineración inadecuada de esas sustancias es altamente nociva para el medio ambiente; la incineración de cinco litros de aceite provocaría la contaminación del volumen de aire que respira una persona durante tres años, y si los vierten en suelo o en las aguas superficiales y subterráneas, eliminan la fertilidad de las tierras al impedir el normal desarrollo de su actividad biológica y química. ${ }^{9}$

Por tanto, en el desarrollo de este trabajo se propone demostrar la presencia de compuestos nocivos en los aceites usados a diario para preparar frituras en las cafeterías de la Universidad Santiago de Cali, y que representan un riesgo para la salud de quienes los consumen.

\section{Metodología}

El presente estudio es observacional de corte transversal. Fue desarrollado en las cafeterías de la Universidad Santiago de Cali, lo que permitió describir una situación que genera riesgos para la salud de la comunidad académica.

Es una investigación analítica, pues solo se observa la ocurrencia del fenómeno de las frituras en las cafeterías y los factores relacionados, sin manipular o interferir en él.

Las variables a tener en cuenta son:

a) La temperatura: se mide en grados centígrados y está relacionada con la generación de sustancias tóxicas a partir del calentamiento y la oxidación (reacción con oxígeno atmosférico).

b) La frecuencia de uso del aceite, que está relacionada con la cantidad de veces que se utiliza el aceite y se somete a altas temperaturas.

9 Corte Constitucional de Colombia. SENTENCIA T-204 de 2003. (M.P. Clara Inés Vargas Hernández; marzo 4 de 2004). Disponible en https://www.corteconstitucional.gov.co/ relatoria/2004/T-204-04.htm 
Para el presente estudio, el universo lo constituyeron siete de las cafeterías del campus universitario que preparen frituras.

La universidad tiene tres jornadas de estudio (mañana, tarde y noche), de modo que se escogieron como muestra las siete cafeterías más grandes con el consentimiento de la alta dirección de la universidad a través de la Gerencia Administrativa, y fueron seleccionadas de acuerdo con la mayor afluencia de público y porque venden gran cantidad de alimentos fritos.

Se diseñó una ficha de recolección de información, que consta de tres partes:

- Identificación del establecimiento.

- Datos sobre aceite y usos (frecuencia de uso, alimentos que se preparan, etc.).

- Toma de temperatura directamente del recipiente de fritura y recolección de muestras de aceite sin usar y usado.

Para alcanzar los objetivos propuestos, el estudio se dividió en tres partes:

a) A través del método del ácido tiobarbitúrico, se detectó malonaldehído en las muestras de las cafeterías y las réplicas.

b) Se compararon los resultados de las muestras con las réplicas experimentales.

c) Se diseñó la estrategia de educación ambiental, cuya primera actividad de sensibilización se desarrolló con una muestra de la comunidad estudiantil.

La parte experimental de este estudio comienza con la detección del malonaldehído a partir de una prueba en laboratorio controlada, articulada con otra prueba de recolección de muestras en las cafeterías y seguida de un análisis experimental.

Para la detección del malonaldehído, se tomaron como referencia tres clases de aceites de cocina y un aceite de grasa sólida, con el fin de recrear en el laboratorio situaciones posibles a las que son sometidos los lípidos utilizados en la preparación de frituras. De igual forma, se realizó una prueba que consiste en recolectar muestras de aceites de diferentes establecimientos comerciales donde se expenden frituras en las cafeterías de la Universidad Santiago de Cali, teniendo como parámetro importante la toma de la temperatura a la cual está siendo sometido el lípido y el número de veces que ha sido reutilizado.

A las muestras recolectadas se les midió la absorbancia con luz visible. Después de la toma de muestras y la realización de la prueba de espectrofotometría, 
se compararon los resultados obtenidos con las muestras de las dos pruebas para generar conclusiones sobre la formación de sustancias tóxicas, específicamente la detección de malonaldehído y la consecuente pérdida de las propiedades originales de los aceites. Se hizo el análisis respectivo de los resultados.

Para llevar a cabo la segunda prueba, se visitaron los sitios seleccionados del campus universitario y se recolectaron muestras duplicadas del recipiente donde se preparan las frituras y del envase original. La toma de muestras va acompañada del diligenciamiento de la ficha de recolección de muestras, en la que se consignaron datos importantes como identificación del local, tiempo de uso del lípido, número de veces de reutilización y temperatura a la cual estaba expuesto al momento de realizar el muestreo.

Después de la recolección de las muestras, se realizó el respectivo análisis experimental con el espectrofotómetro visible a una longitud de onda de $540 \mathrm{~nm}$. Para calcular el valor de la prueba, se utiliza la siguiente fórmula:

$$
\text { Valor prueba de TBA }=\frac{\text { (absorbancia problema }- \text { absorbancia blanco) }}{\text { Peso de la muestra }}
$$

Valores de TBA (ácido tiobarbitúrico) mayores o iguales a 1 son considerados altos y en general valores por encima de 0,7 son de importancia en el manejo de alimentos.

\section{RESULTADOS}

En la tabla 1, se presentan los resultados del análisis físico-químico de las frituras de las diferentes cafeterías objeto de este estudio y los controles realizados en el laboratorio. 
Tabla 1. Detección de malonaldehído

\begin{tabular}{|c|c|c|c|c|c|c|c|}
\hline Ítem & Restaurante & $\begin{array}{c}\text { Prom } \\
\text { Muestra }\end{array}$ & $\begin{array}{l}\text { Prom } \\
\text { Blanco }\end{array}$ & $\begin{array}{c}\text { Valor } \\
\text { prueba } \\
\text { TBA }\end{array}$ & $\begin{array}{c}\text { Color prueba } \\
\text { TBA }\end{array}$ & pH & $\mathbf{T}\left({ }^{\circ} \mathrm{C}\right)$ \\
\hline 1 & Papitodo (usado) & 0,04 & 0 & 0,683 & Anaranjado & 6.2 & 135 \\
\hline 2 & Papitodo (nuevo) & $-0,042$ & $-0,001$ & $-0,683$ & Amarillo claro & 9.2 & 36 \\
\hline 3 & Rincón Gourmet (usado) & 0,048 & $-0,002$ & 0,833 & Anaranjado & 8.9 & 138 \\
\hline 4 & Rincón Gourmet (nuevo) & $-0,048$ & $-0,001$ & $-0,783$ & Anaranjado & 9.9 & 38 \\
\hline 5 & Paola (usado) & 0,059 & $-0,003$ & 1,033 & Anaranjado & 6.6 & 140 \\
\hline 6 & Paola (nuevo) & $-05,054$ & 0,000 & $-0,900$ & Amarillo & 8.8 & 37 \\
\hline 7 & Pollo Loco (usado) & 0,158 & $-0,001$ & 2,650 & Anaranjado & 6.1 & 145 \\
\hline 8 & Pollo Loco (nuevo) & $-0,056$ & $-0,001$ & $-0,917$ & Amarillo claro & 8,0 & 36 \\
\hline 9 & Integrales (usado) & 0,076 & 0 & 1,267 & Anaranjado & 8,2 & 140 \\
\hline 10 & Integrales (nuevo) & 0,039 & 0 & 0,650 & Amarillo intenso & 8,4 & 37 \\
\hline 11 & A1 Control & 0,024 & 0,001 & 0,383 & Anaranjado & 7,7 & 37 \\
\hline 12 & A1 Muestra 1 & 0,123 & 0,001 & 2,033 & Anaranjado & 6 & 100 \\
\hline 14 & A1 Muestra 3 & 0,126 & 0 & 2,100 & Amarillo intenso & 8,8 & Más 200 \\
\hline 19 & A1 Recalentado $150^{\circ} \mathrm{C}$ & 0,063 & 0 & 1,050 & Amarillo & 8,3 & 150 \\
\hline 20 & A1 Recalentado $200^{\circ} \mathrm{C}$ & 0,037 & 0,001 & 0,600 & Amarillo & 5,5 & 200 \\
\hline 21 & A2 Control & $-0,041$ & 0,001 & $-0,700$ & $\begin{array}{l}\text { Amarillo muy } \\
\text { claro }\end{array}$ & 8,7 & 39 \\
\hline 22 & A2 Muestra 1 & 0,487 & 0 & 8,117 & $\begin{array}{c}\text { Anaranjado } \\
\text { claro }\end{array}$ & 5 & 100 \\
\hline 24 & A2 Muestra 3 & 0,135 & 0,002 & 2,217 & Amarillo intenso & 8,2 & Más 200 \\
\hline 25 & A2 Recalentado $150^{\circ} \mathrm{C}$ & 1,624 & 0 & 27,067 & Anaranjado & 8,3 & 150 \\
\hline 26 & A2 Recalentado $200^{\circ} \mathrm{C}$ & 0,76 & 0 & 12,667 & Anaranjado & 7,7 & 200 \\
\hline 27 & A3 Control & 0,004 & 0,000 & 0,067 & Amarillo claro & 10,8 & 38 \\
\hline 28 & A3 Muestra 1 & 0,093 & 0,001 & 1,533 & Amarillo intenso & 6 & 100 \\
\hline 30 & A3 Muestra 3 & 0,207 & 0 & 3,450 & Amarillo claro & 7,6 & Más 200 \\
\hline 31 & A3 Recalentado $150^{\circ} \mathrm{C}$ & 2,694 & $-0,001$ & 44,917 & Anaranjado & 8,5 & 150 \\
\hline 32 & A3 Recalentado $200^{\circ} \mathrm{C}$ & 0,466 & 0 & 7,767 & Anaranjado & 9,1 & 200 \\
\hline 33 & A4 Control & 0,012 & 0 & 0,200 & Amarillo claro & 10,5 & 39 \\
\hline 34 & A4 Muestra 1 & 0,921 & 0,000 & 15,350 & Anaranjado & 5 & 100 \\
\hline 36 & A4 Muestra 3 & 0,178 & 0 & 2,967 & Amarillo & 8,7 & Más 200 \\
\hline 37 & A4 Recalentado $150^{\circ} \mathrm{C}$ & 0,364 & $-0,001$ & 6,083 & Anaranjado & 6,5 & 150 \\
\hline 38 & A4 Recalentado $200^{\circ} \mathrm{C}$ & 0,799 & 0,001 & 13,300 & Anaranjado & 9,5 & 200 \\
\hline
\end{tabular}

Fuente: elaboración propia. 


\section{Análisis comparativo de las características fisicoquímicas de las muestras de frituras de las cafeterías versus los controles}

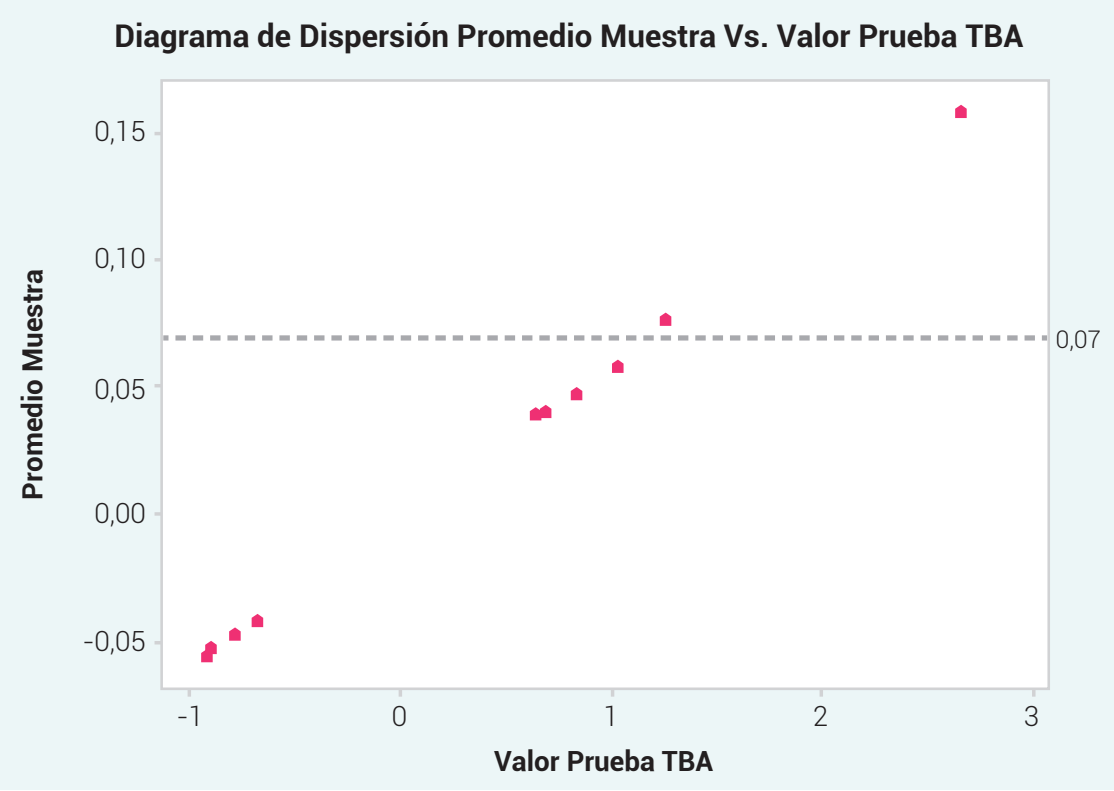

Figura 1. Promedio de muestras vs. prueba TBA

Fuente: spss, versión 13.

Cada punto del gráfico representa un par ordenado con las dos mediciones para cada establecimiento. Se observa claramente que existe una relación de proporcionalidad (directa) entre las dos mediciones; esto es, a mayor valor del promedio de la muestra, mayores tienden a ser los valores obtenidos por la prueba TBA. Para establecer una medida numérica de dicha asociación, se calculó un coeficiente de correlación de rangos de Spearman, con lo que se obtuvo un valor de 100 \% (correlación perfecta), con un valor $\mathrm{P}$ de la prueba menor al $1 \%$.

El valor de 0,07 corresponde a la referencia positiva para determinación de aldehídos en aceites recalentados. 


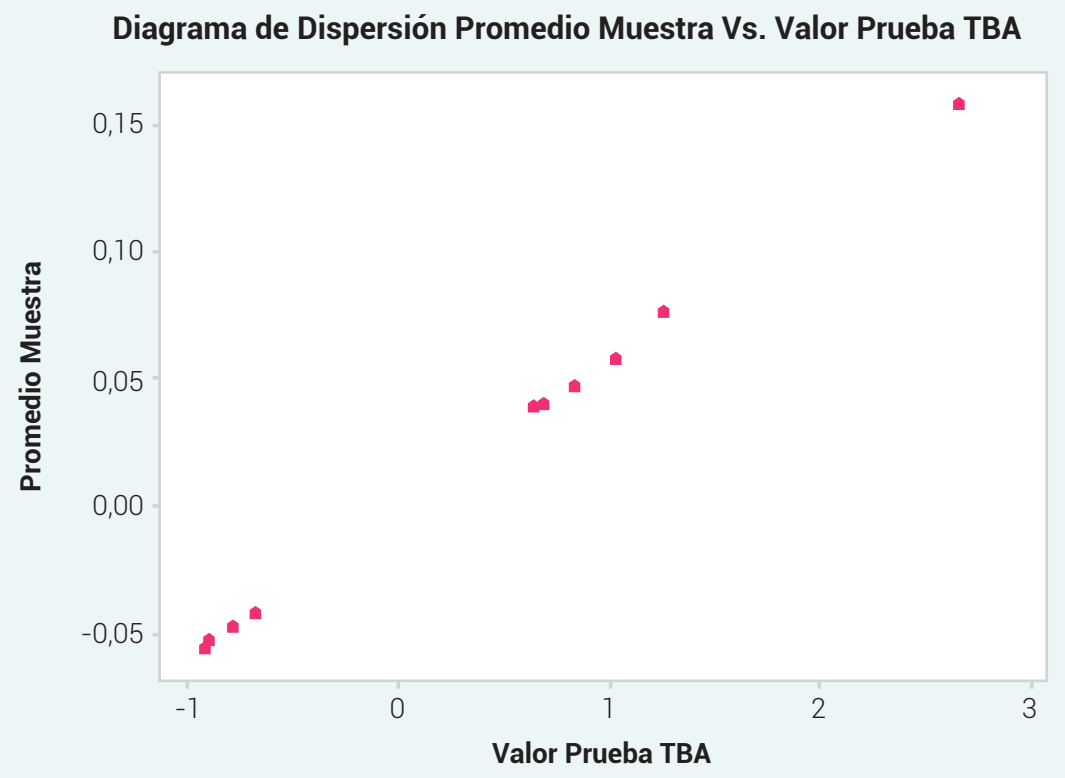

Figura 2. Promedio de muestras vs. prueba TBA (observaciones vs. control) Fuente: SPSS, versión 13.

Diagrama de Dispersión Promedio muestra vs. Valor Prueba TBA (Controles)

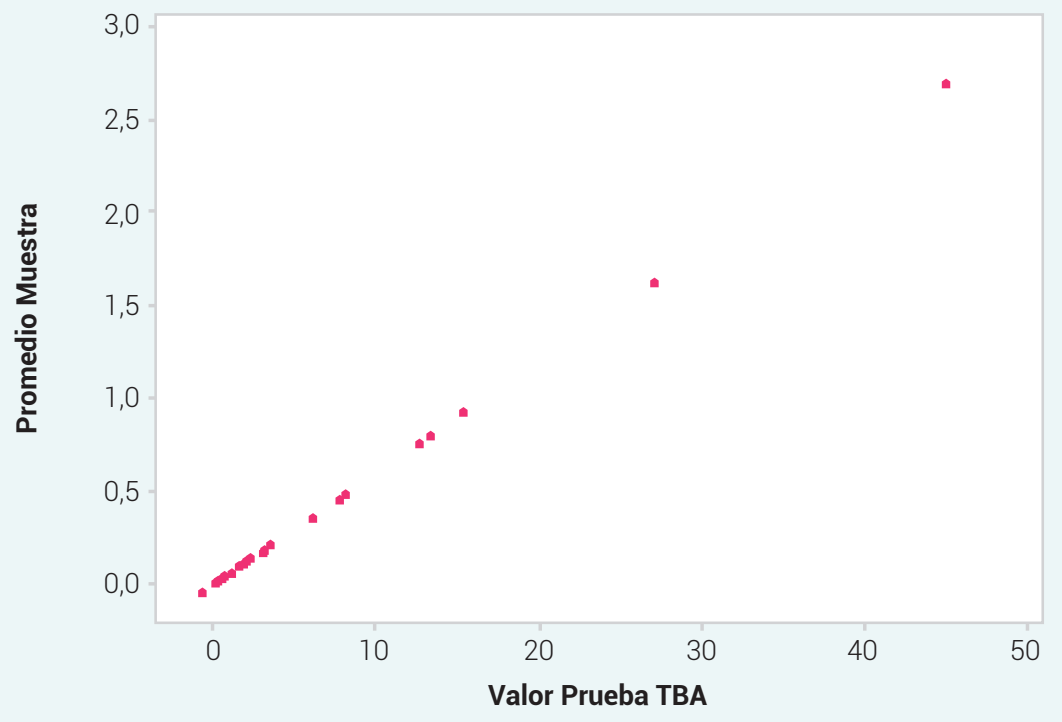

Figura 3. Promedio de muestras vs. prueba TBA (observaciones vs. control) Fuente: sPSS, versión 13. 
En estos dos gráficos, se han relacionado los valores promedio de la muestra con el valor obtenido para la prueba TBA tanto para el caso de las mediciones (gráfico de la izquierda ), como para el caso de los controles (gráfico de la derecha ). Se observa claramente que la relación de proporcionalidad entre las dos variables se mantiene también para el caso de los controles, aun cuando se puede apreciar que el rango de variación de los valores difiere en las dos muestras.

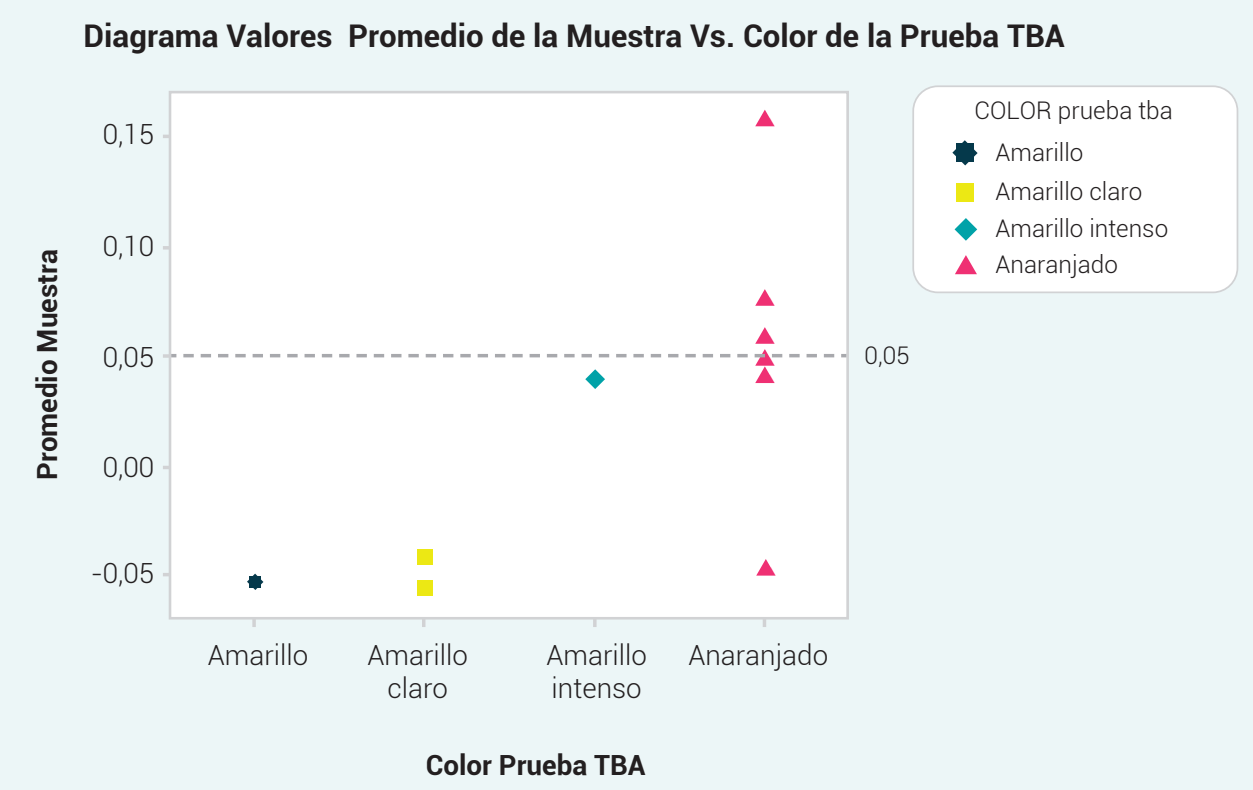

Figura 4. Promedio de muestras vs. color (observaciones vs. control) Fuente: spss, versión 13. 


\section{Diagrama Valores Promedio de la Prueba Vs. Color de la Prueba TBA (Controles)}

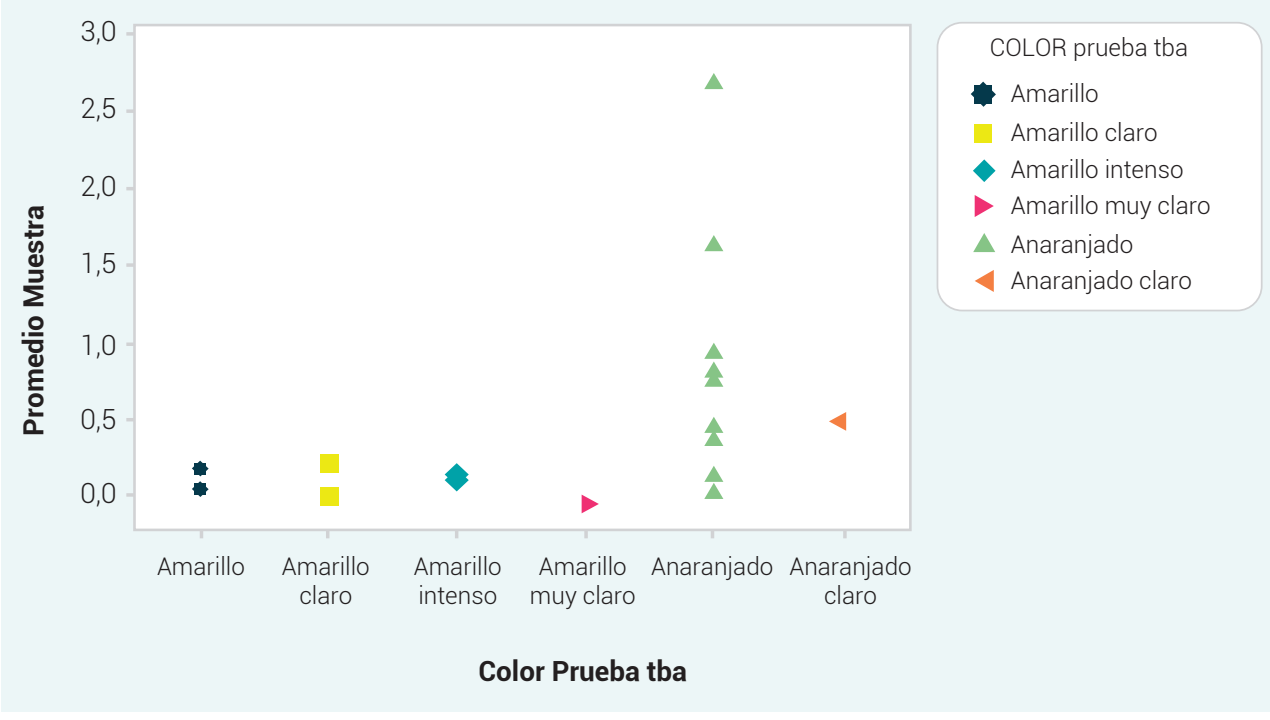

Figura 5. Diagrama de valores de prueba vs. color de la prueba TBA Fuente: spss, versión 13.

En estos gráficos se han relacionado los valores promedio de la muestra, contra los colores obtenidos en la prueba TBA. De nuevo, a pesar que el rango de variación de los valores obtenidos en cada muestra difiere (las mediciones vs. controles), si se observa que los valores tienden a concentrarse en el color Anaranjado para cada una de las muestras, mostrando una distribución relativamente similar, en torno a este color en particular.

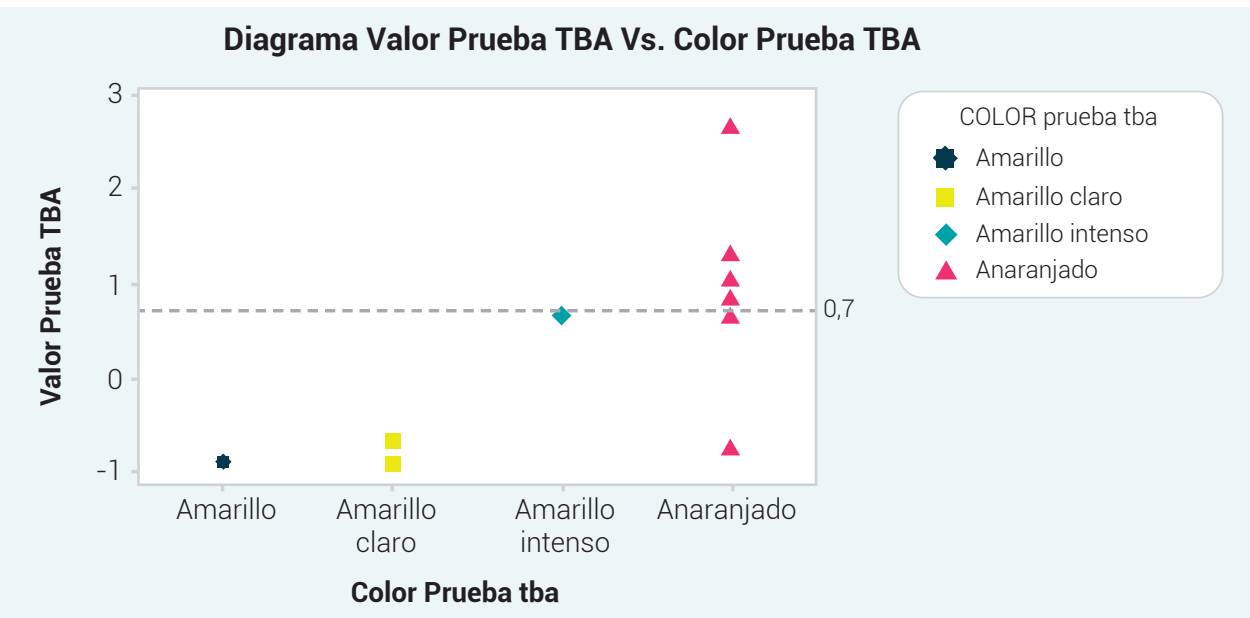

Figura 6. Prueba TBA vs. color (observaciones vs. control)

Fuente: sPSS, versión 13. 


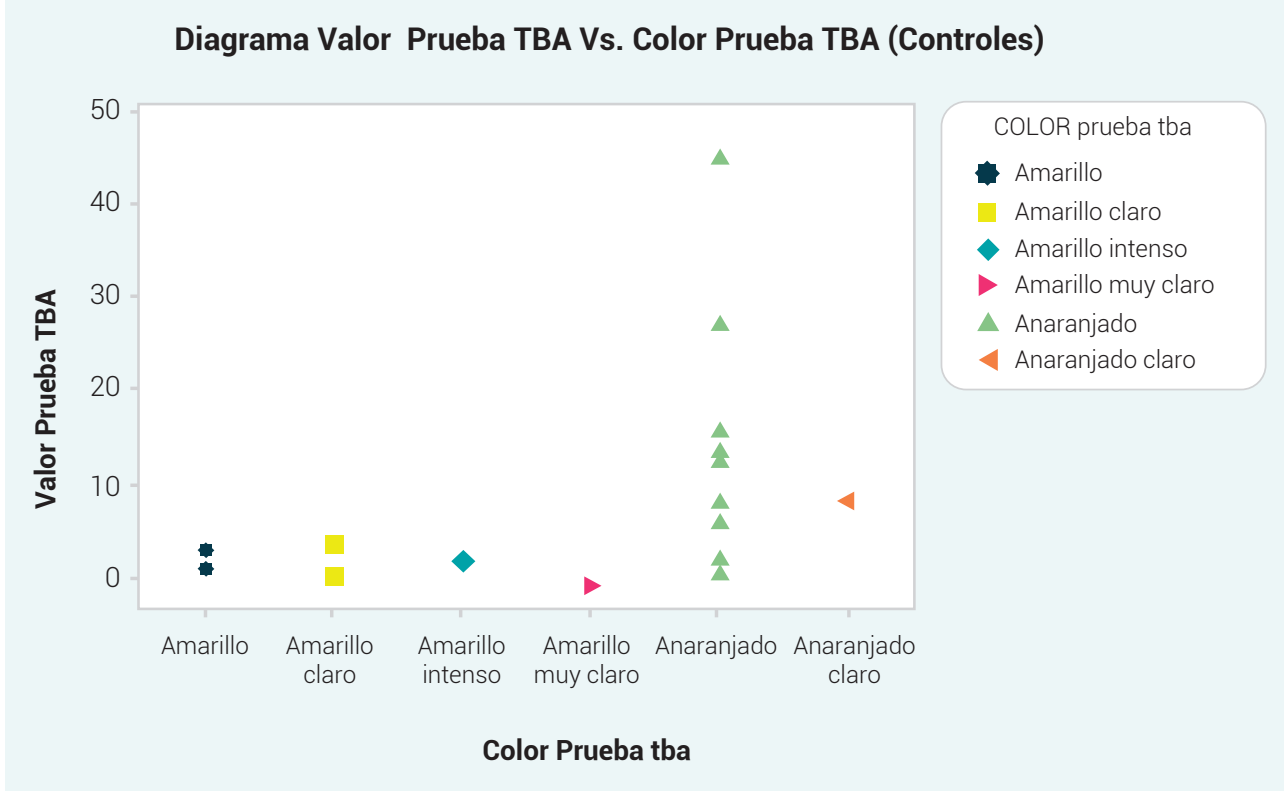

Figura 7. Diagrama valor prueba TBA vs. color prueba TBA Fuente: sPSS, versión 13.

En estos gráficos se observa, muy a pesar que las escalas de medición obtenidas difieren, tanto para los valores medidos, como para los controles, que los valores de la prueba TBA se concentran de forma relativamente similar en el color "Anaranjado", considerado como positivo para el complejo de unión entre el aldehído y el TBA.

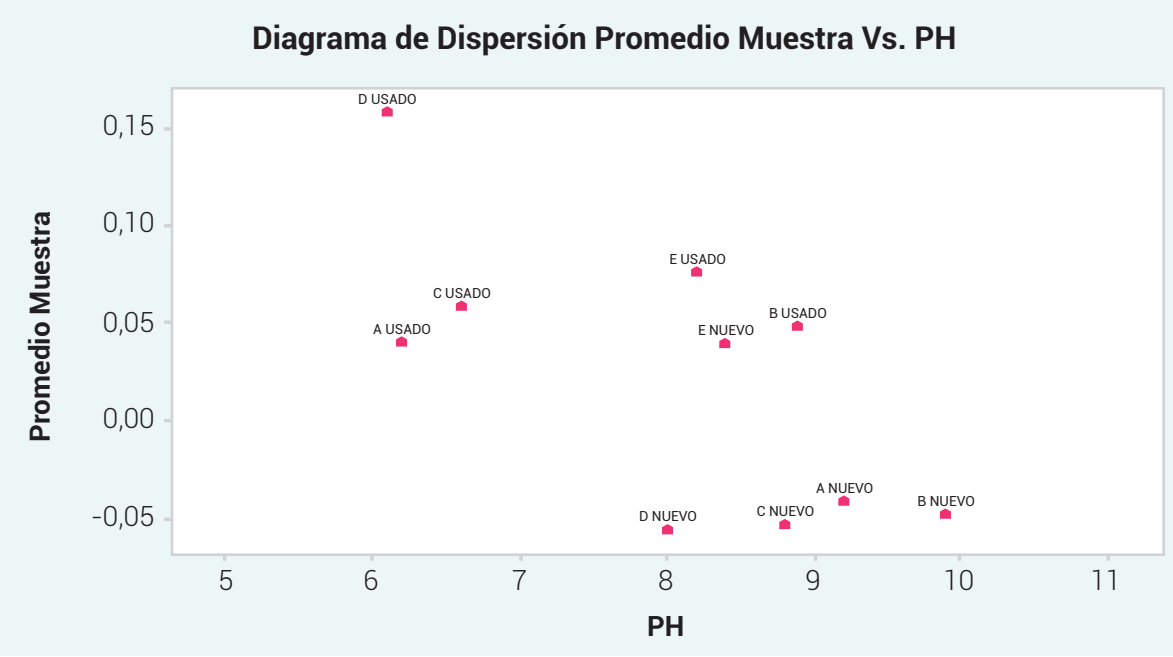

Figura 8. Promedio de muestra vs. pH (observaciones vs. control) Fuente: spss, versión 13. 


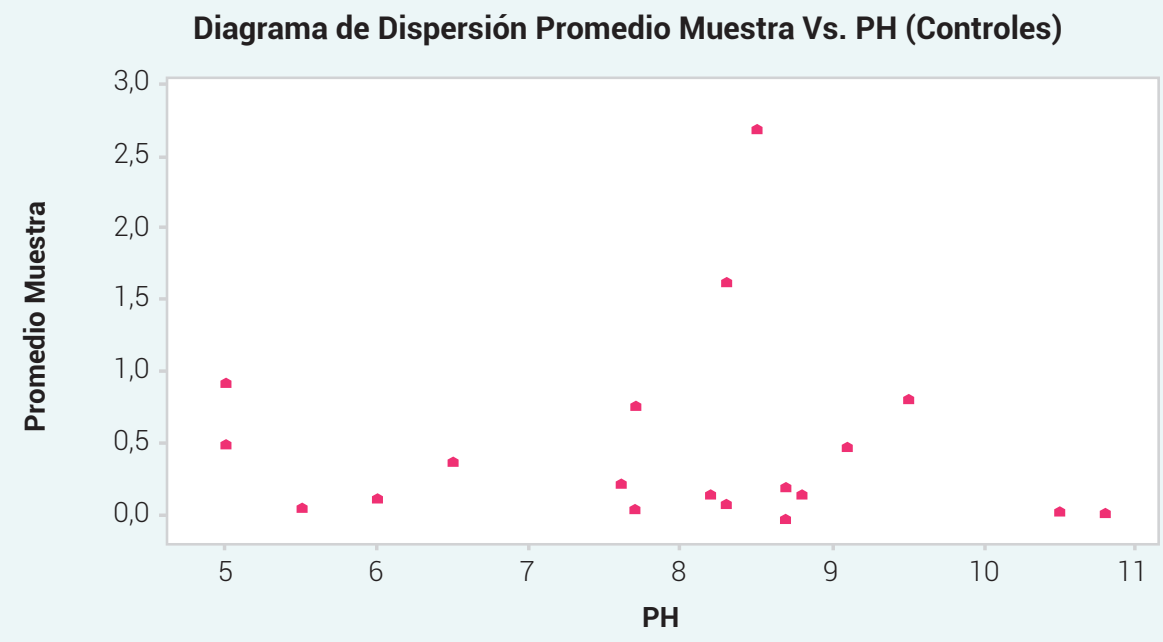

Figura 9. Diagrama de dispersión promedio muestra vs. pH Fuente: spss, versión 13.

En estos diagramas de dispersión, se han relacionado los valores del valor promedio de la muestra, con respecto al valor obtenido en las mediciones del pH en cada caso. Es interesante notar que en cada muestra (mediciones y controles), la mayor cantidad de observaciones en cada gráfico (como proporción), se agrupan en torno a los valores de 8,9 y 10 en la escala de las mediciones del pH.

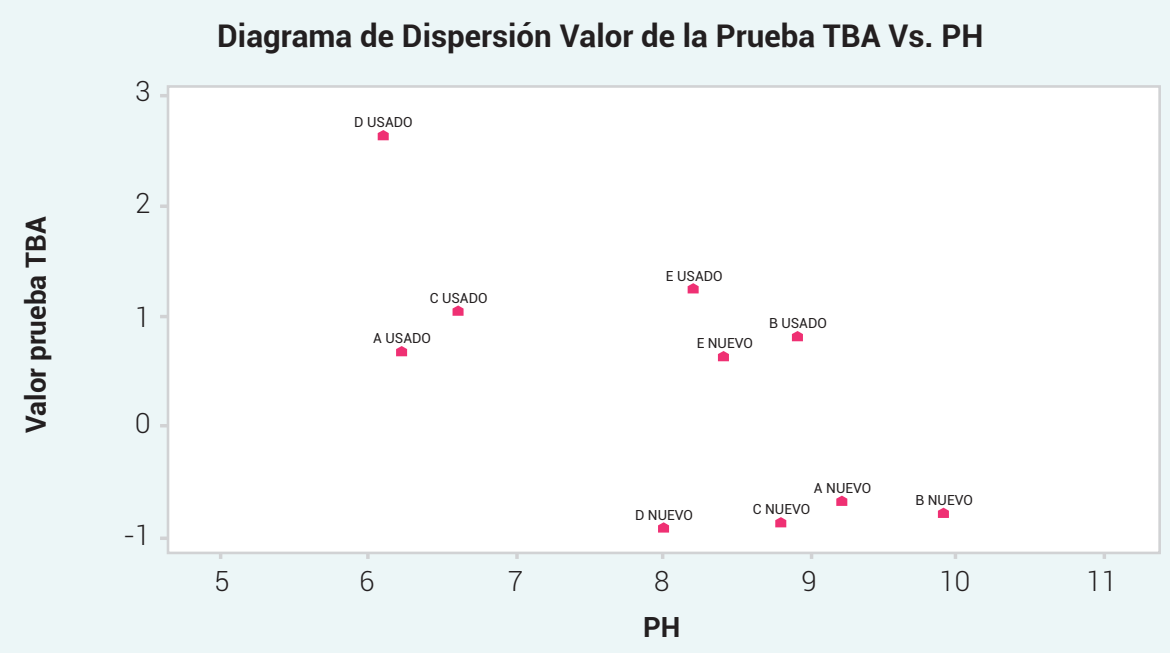

Figura 10. Prueba TBA vs. pH (observaciones vs. control) Fuente: SPSS, versión 13. 


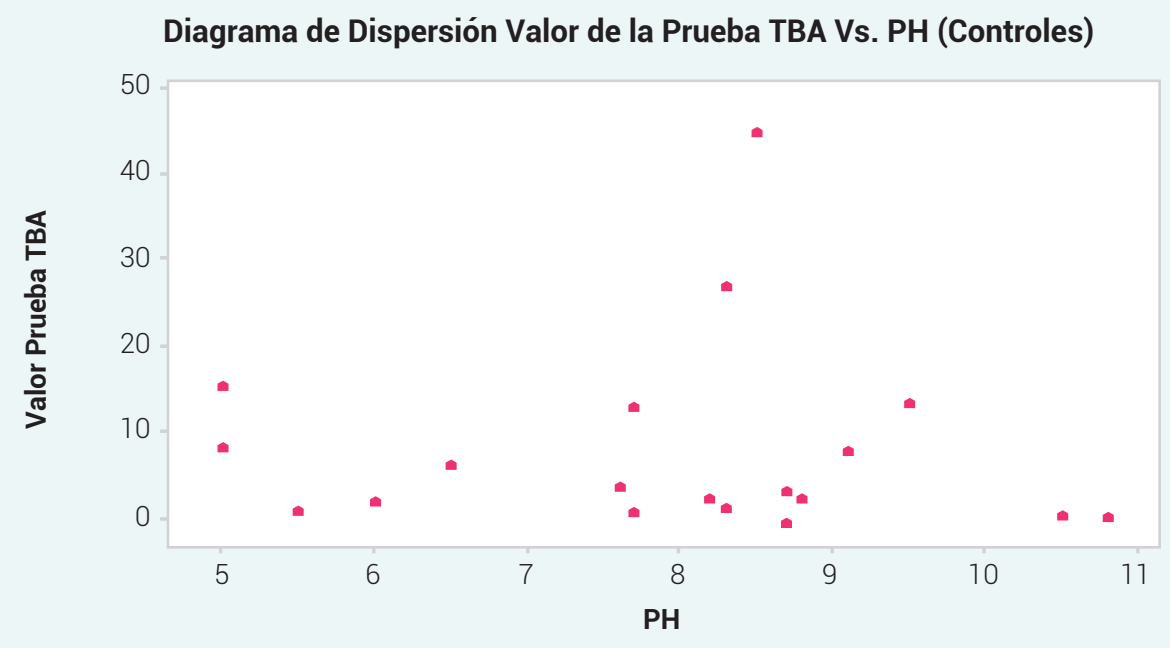

Figura 11. Diagrama de dispersión valor de la prueba TBA Fuente: spss, versión 13.

En estos diagramas de dispersión, se han relacionado los valores de la prueba TBA, con respecto al valor obtenido en las mediciones del pH en cada caso. Es interesante notar que, en cada muestra, la mayor cantidad de observaciones en cada gráfico (como proporción), se agrupan en torno a los valores de 8, 9 y 10 en la escala de las mediciones del $\mathrm{pH}$.

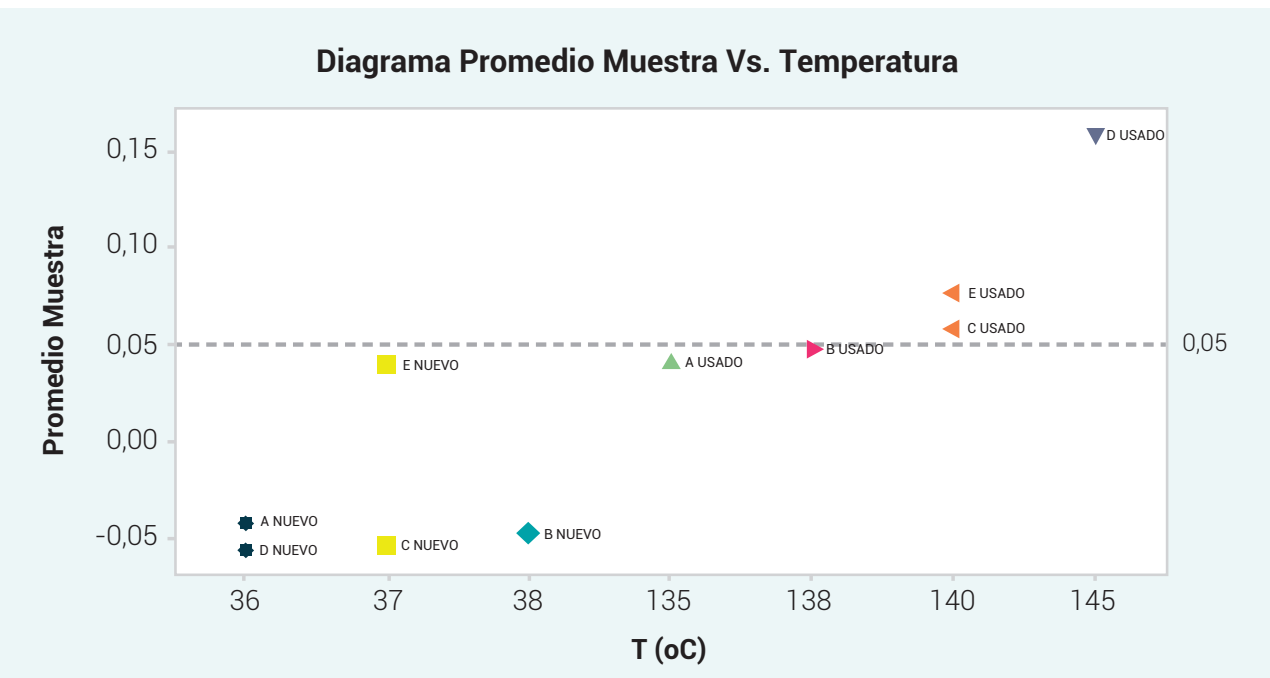

Figura 12. Promedio de muestra vs. temperatura (observaciones vs. control) Fuente: spSS, versión 13. 


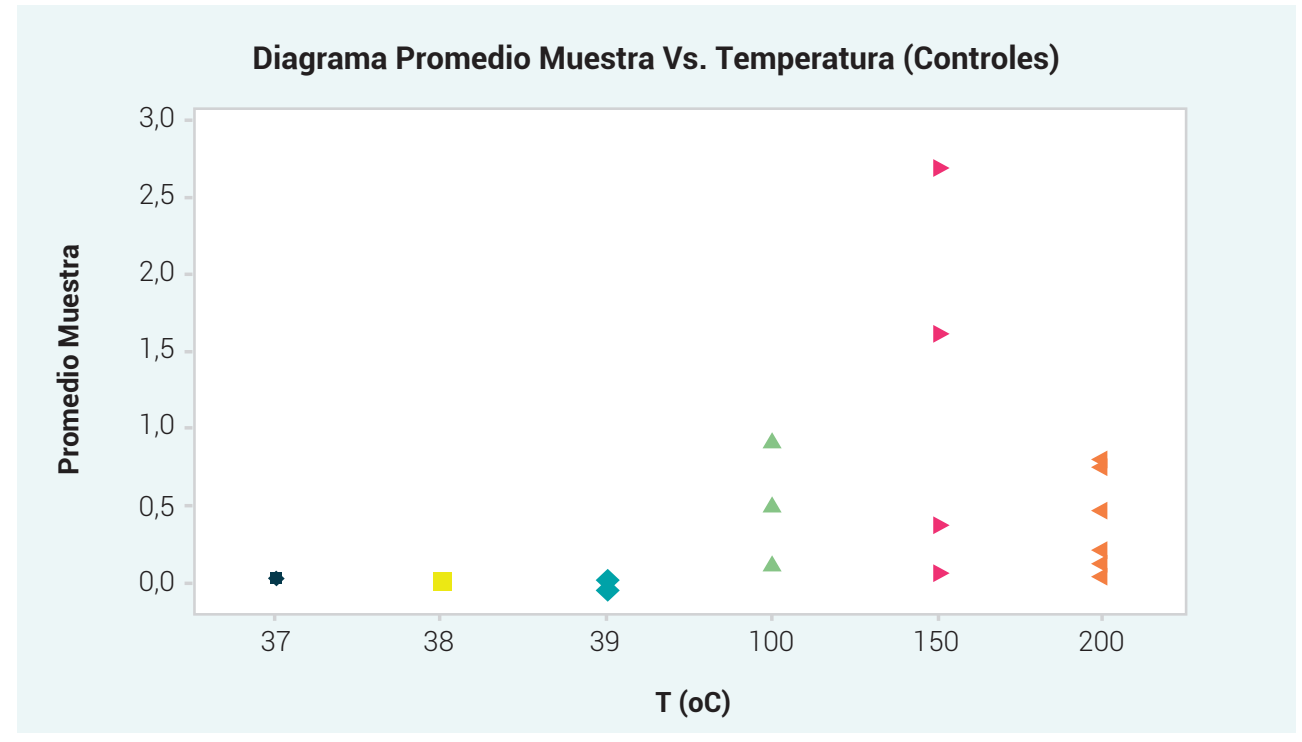

Figura 13. Diagrama promedio muestra vs. temperatura Fuente: spss, versión 13.

Estos gráficos relacionan los valores promedio de la muestra de absorbancia con respecto a la temperatura en grados centígrados. Es importante anotar cómo se da una especie de "frontera" entre los valores obtenidos para las mediciones a una temperatura de $135^{\circ} \mathrm{C}$ y el valor de referencia de 0,05 de absorbancia indicando claramente diferencias en los valores obtenidos en las mediciones del promedio de la muestra con relación a la cualidad nuevo/usado del aceite, para cada uno de los establecimientos.

Aunque esta comparación no es tan adecuada, pues las mediciones de promedio muestra para los controles fueron obtenidos a diferentes temperaturas que los de la muestra. Pero se puede observar como los valores de la muestra presentan comportamientos interesantes en las temperaturas entre aceites usados y nuevos en cada una de las cafeterías. 


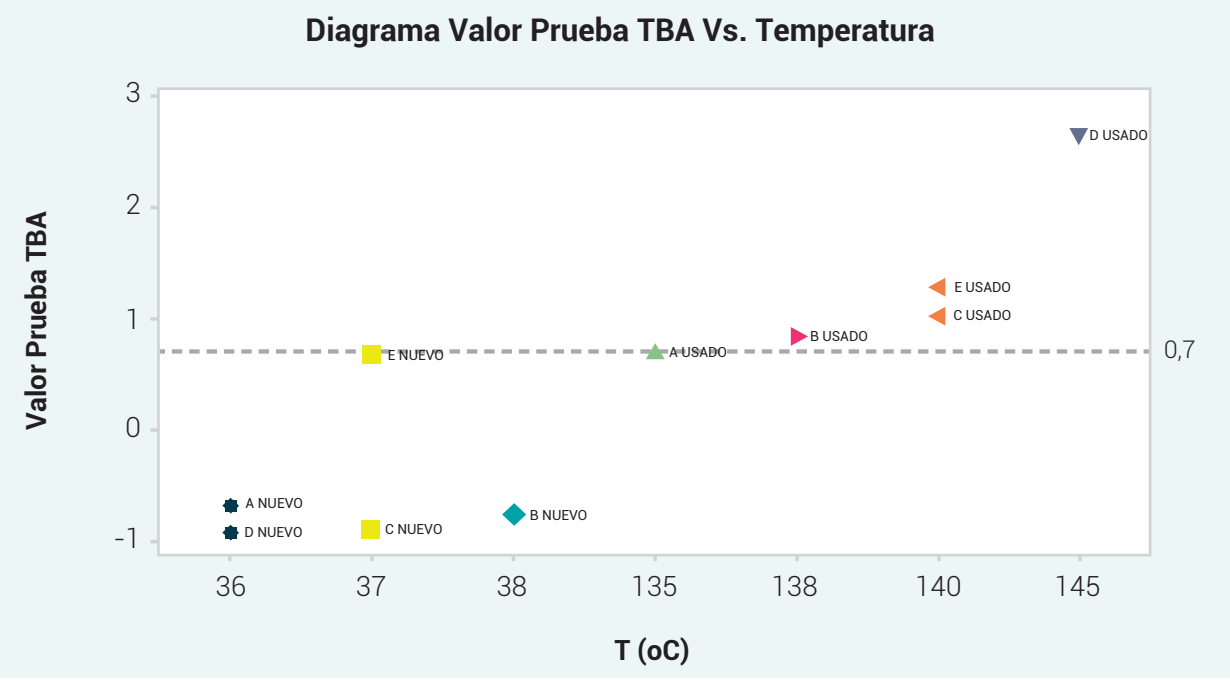

Figura 14. Prueba TBA vs. temperatura Fuente: sPSS, versión 13.

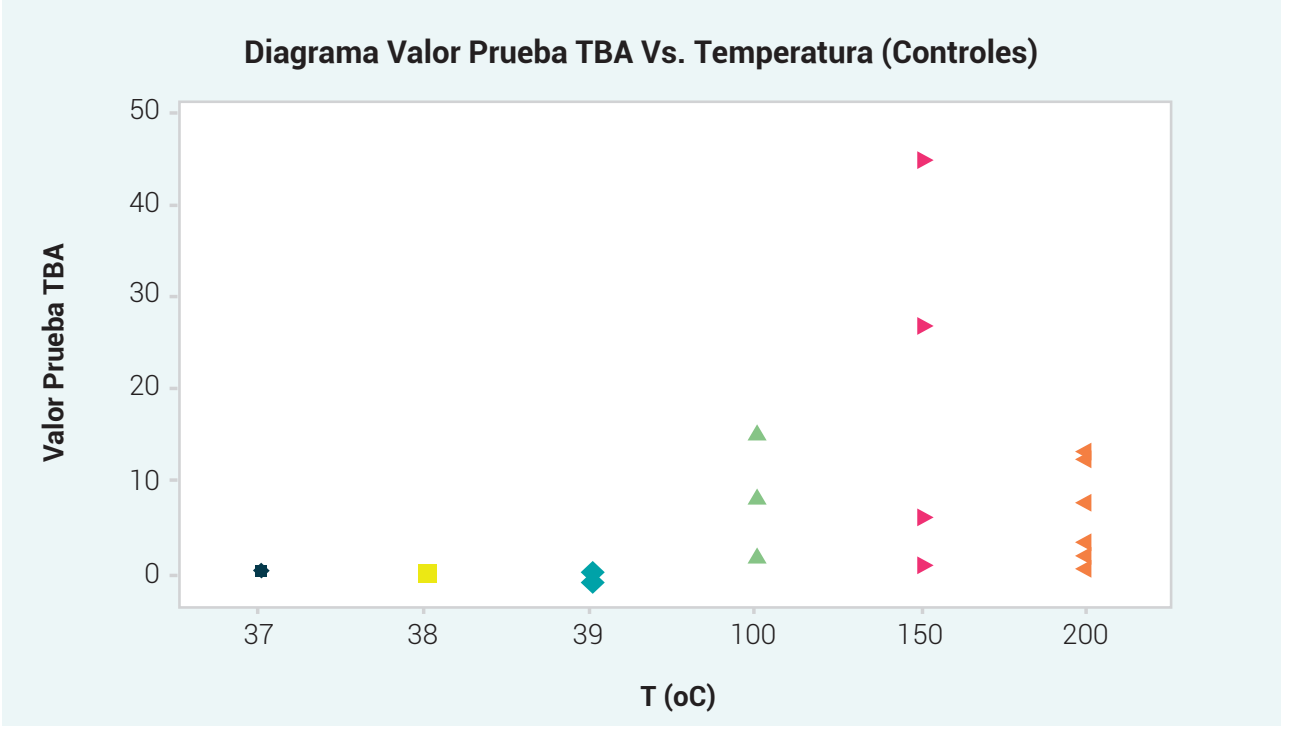

Figura 15. Diagrama Valor Prueba TBA Vs Temperatura Fuente: sPSs, versión 13.

Estos gráficos relacionan los valores promedio de la prueba TBA con respecto a la temperatura en grados centígrados. Es importante observar cómo se da una especie de "frontera" entre los valores obtenidos para las mediciones a una temperatura de 
$135^{\circ} \mathrm{C}$ y el valor de referencia de 0,7, indicando claramente diferencias en los valores obtenidos en las mediciones del promedio de la muestra en relación con la cualidad nuevo/usado del aceite para cada uno de los establecimientos.

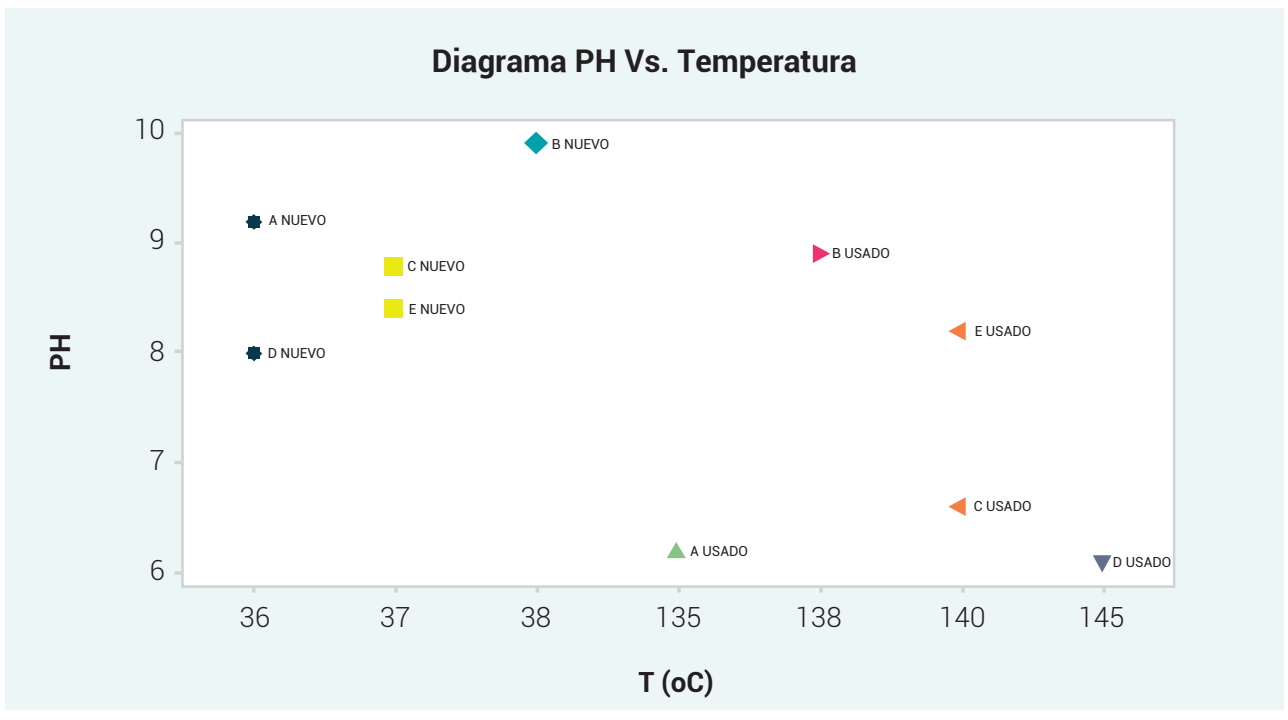

Figura 16. $\mathrm{pH}$ vs. temperatura

Fuente: SPSS, versión 13

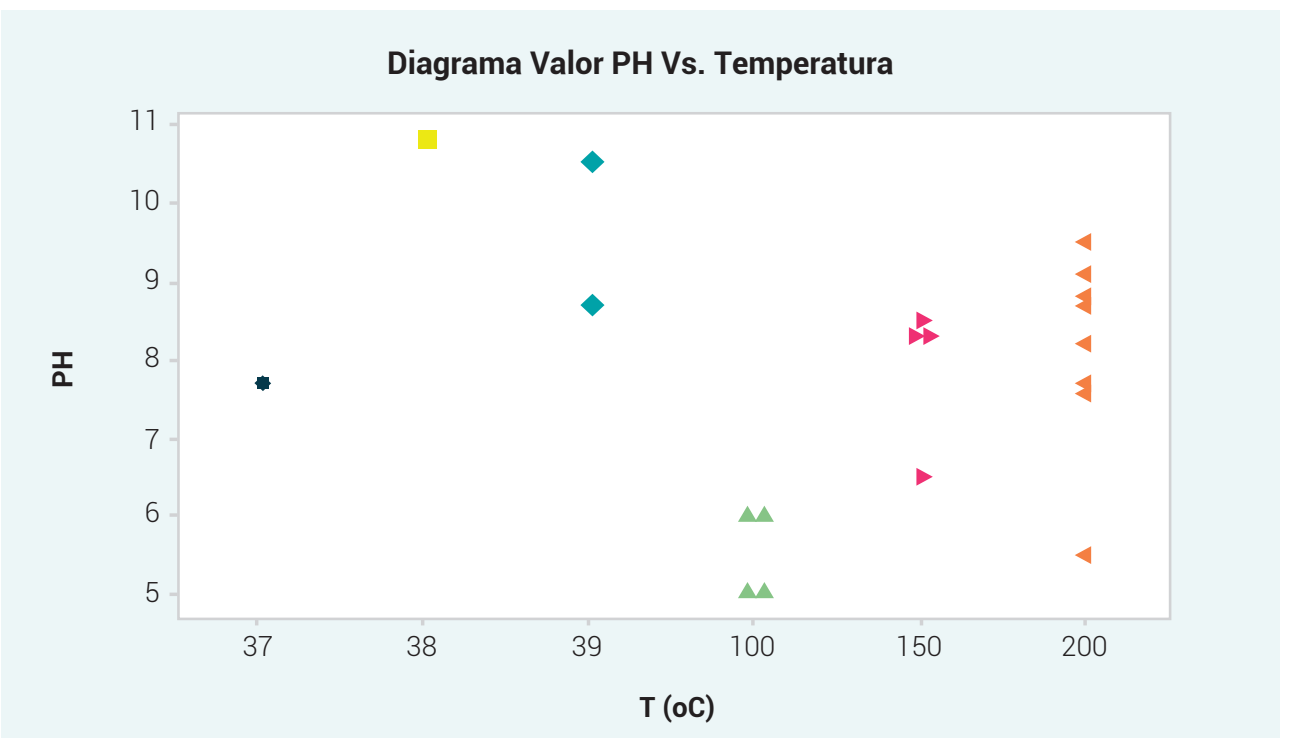

Figura 17. pH vs. temperatura

Fuente: SPSS, versión 13 


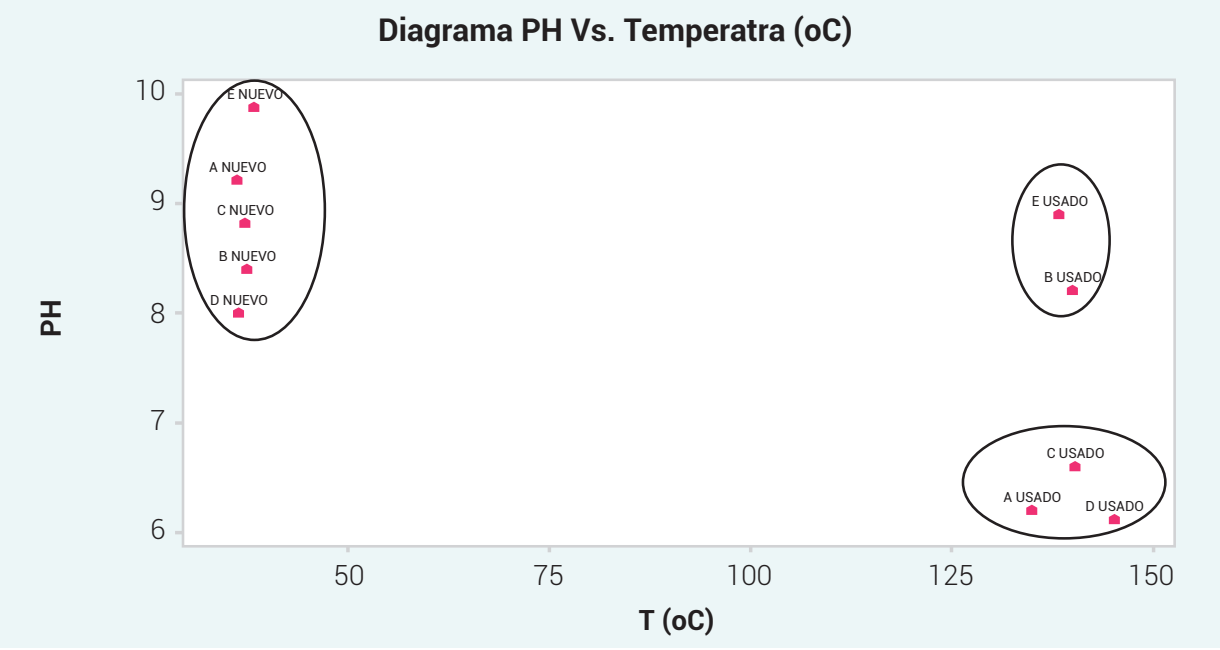

Figura 18. Diagrama pH vs. temperatura Fuente: spss, versión 13.

Es interesante observar las características de tipo cualitativo en este gráfico. Nótese que los valores observados de pH para los aceites "nuevos" en cada establecimiento tienden a mostrar valores superiores en relación con los valores obtenidos para mediciones de $\mathrm{pH}$ para los aceites usados; es decir, muestran mayores valores $\mathrm{pH}$ las mediciones de aceites nuevos que aquellas de aceites usados para cada establecimiento.

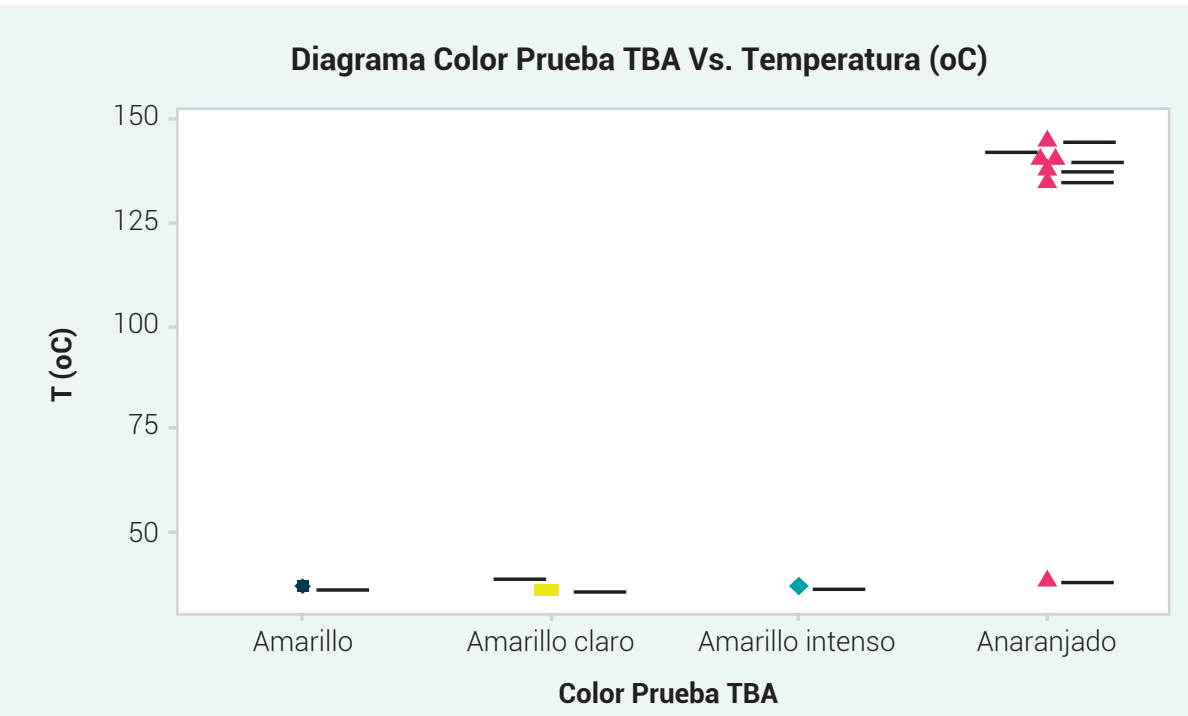

Figura 19. Diagrama color vs. temperatura Fuente: spss, versión 13. 


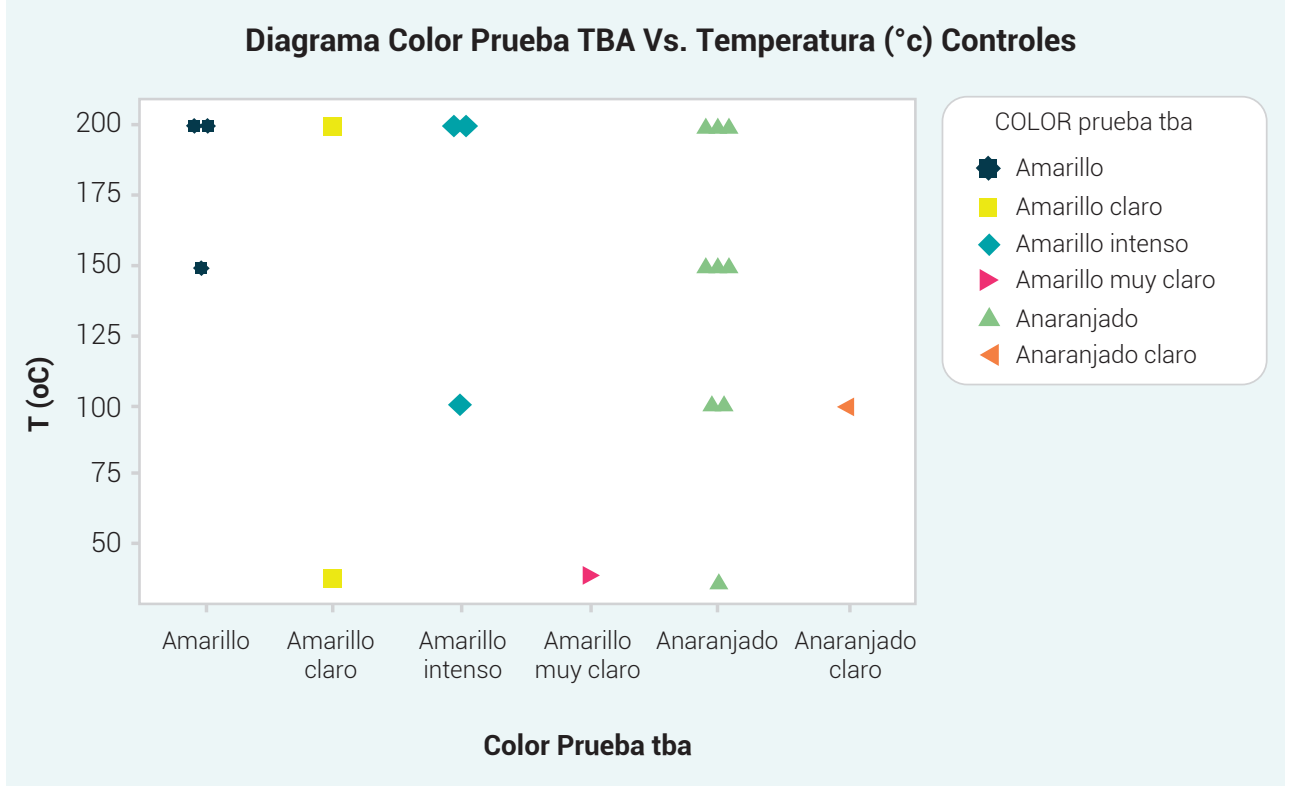

Figura 20. Diagrama color vs. temperatura Fuente: SPSS, versión 13.

Diagrama Promedio Muestra Vs. Establecimientos Usados y Controles

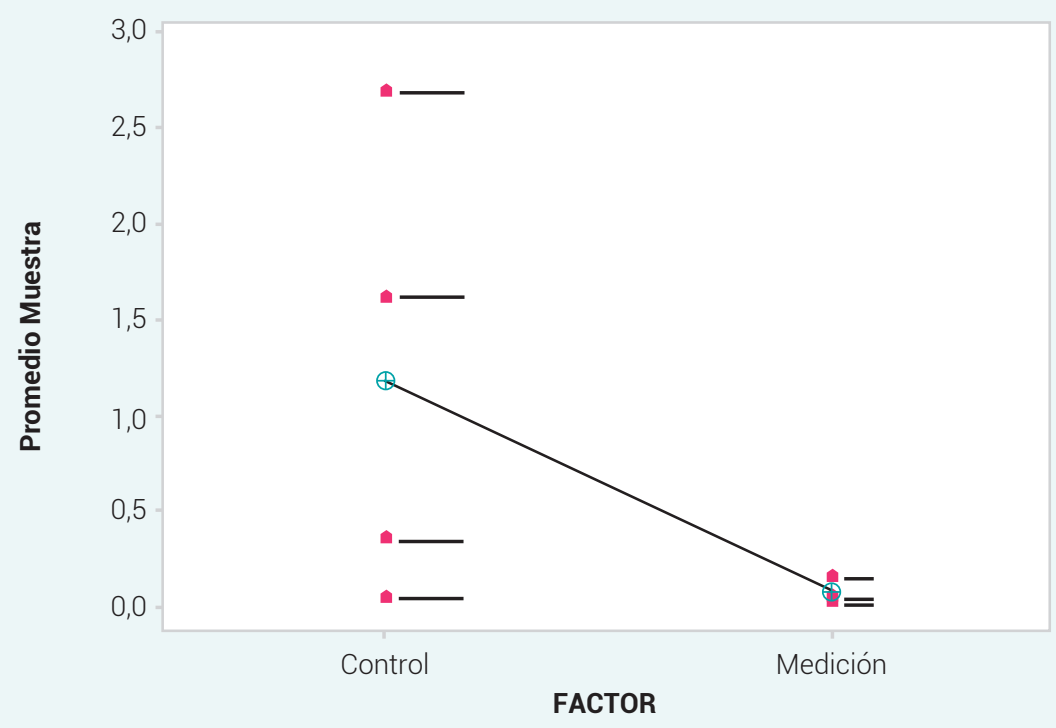

Figura 21. Mediciones con rótulos "usados" vs. recalentados a $150^{\circ} \mathrm{C}$. Fuente: spss, versión 13. 
En el gráfico anterior, se han relacionado los valores promedio de las muestras tanto para los valores medidos, como para sus controles. Se hace evidente que los valores medianos para cada muestra (círculo en color azul) difieren, siendo marcadamente menor para el caso de las mediciones. En relación con su variabilidad relativa (medidos por sus coeficientes de variación respectivos), se observa que a pesar de que el rango de variación de las mediciones difiere para cada muestra, se presenta una menor variabilidad relativa en las mediciones, en comparación a los controles (62,6\% vs. 102,1\%, respectivamente).

Cabe aclarar que las mediciones son muy "concentradas" entre sí (en cuanto a los controles), pero esto no es más que una consecuencia de la diferencia de escalas. Es importante mencionarlo y tener en cuenta los coeficientes de variación respectivos.

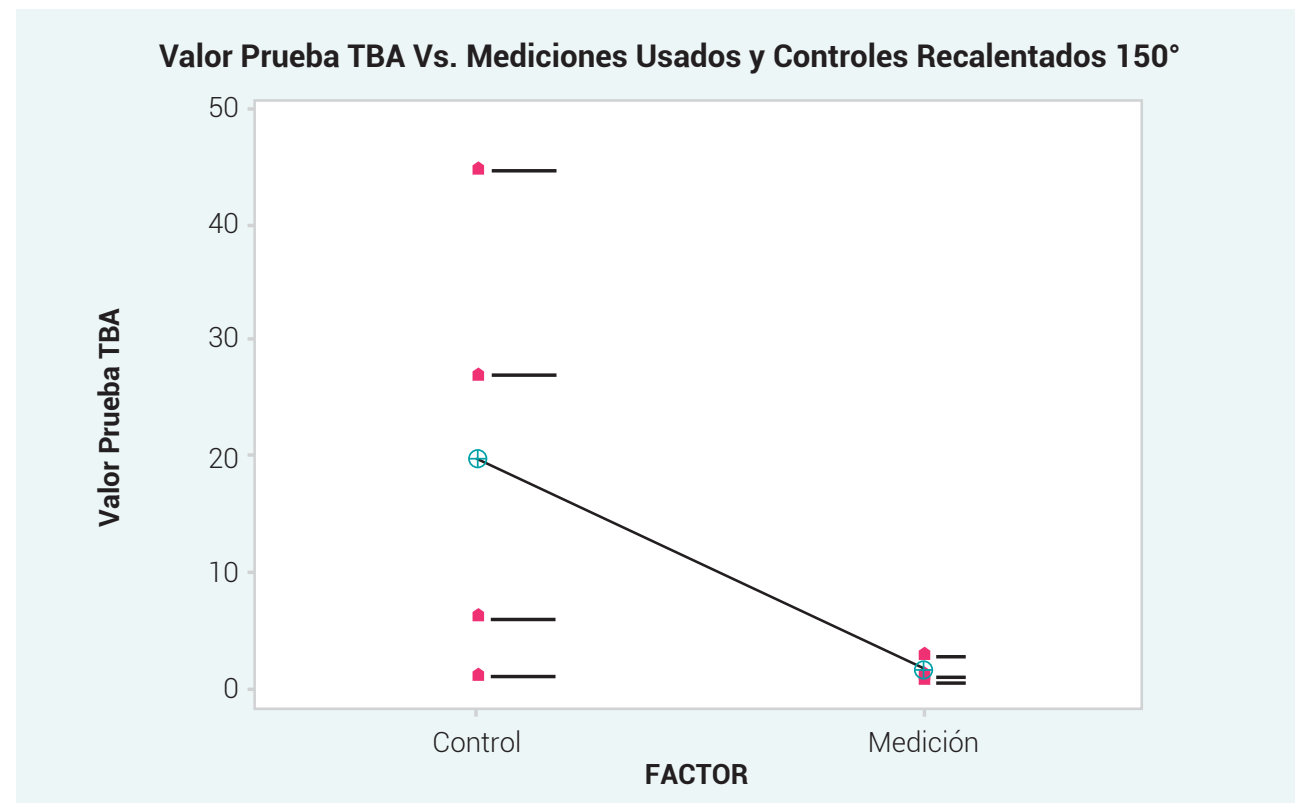

Figura 22. Valor prueba tBA vs. mediciones usadas y controles recalentados $150^{\circ} \mathrm{C}$. Fuente: spss, versión 13.

Es una interpretación similar a la del diagrama anterior, como consecuencia de la fuerte asociación entre las variables promedio muestra vs. valor prueba TBA evidenciada desde el inicio de este informe. 


\section{Diagrama Promedio Muestra Vs. Valor Prueba TBA Según Factor}

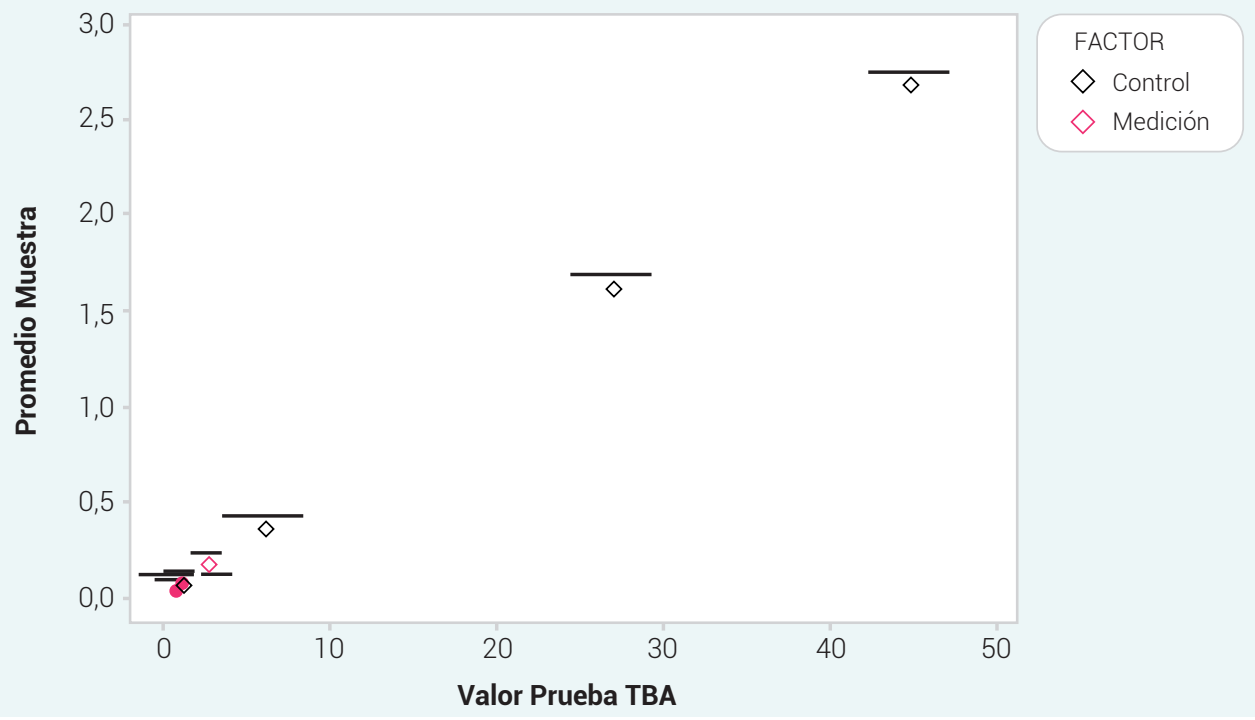

Figura 23. Diagrama promedio muestra vs. valor prueba TBA según factor Fuente: SPSS, versión 13.

El gráfico anterior evidencia la fuerte asociación lineal que presentan las variables promedio muestra vs. valor prueba TBA, mostrando además mayores valores en ambos "pares ordenados" para el caso de los controles, con excepción de una de las observaciones que tiene valores similares a los presentados en las mediciones.

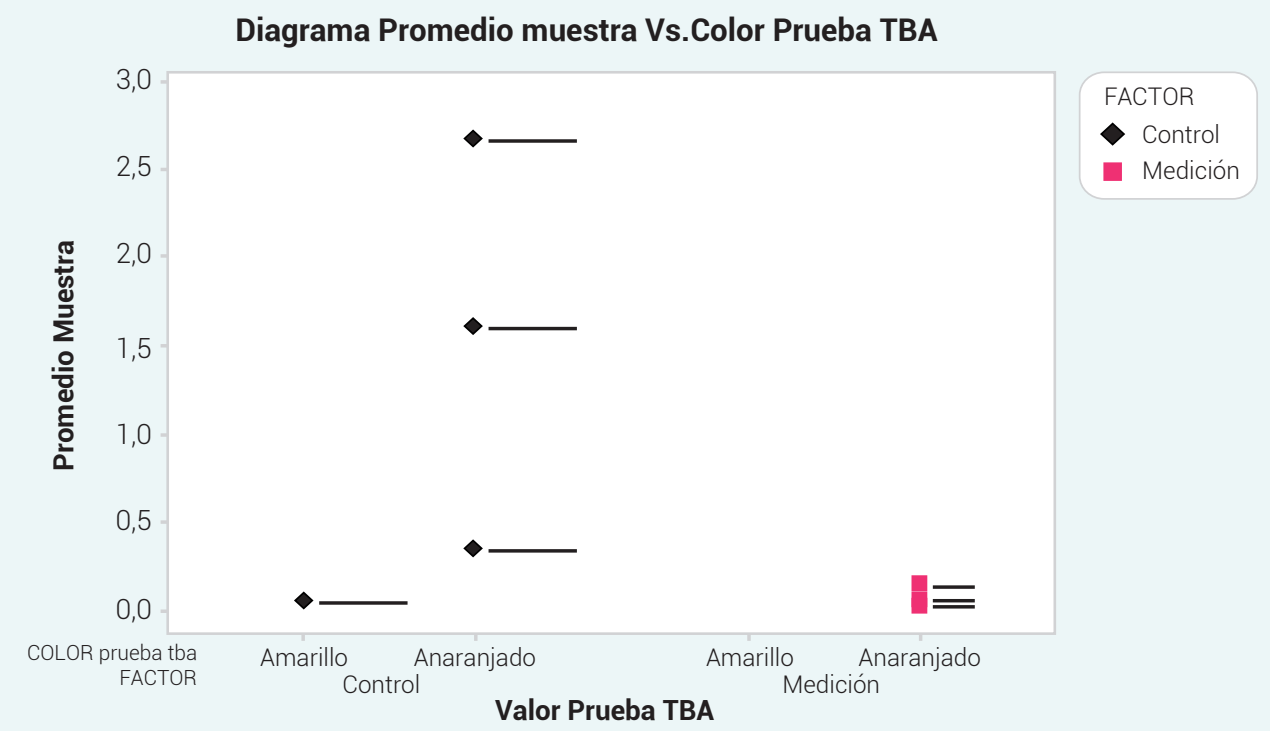

Figura 24. Diagrama promedio muestra vs. color prueba TBA Fuente: spSs, versión 13. 
El gráfico anterior muestra cómo, proporcionalmente hablando, la mayor cantidad de observaciones (tanto para el caso de los controles, como para el caso de las mediciones) se sitúa en torno al color anaranjado derivado de las mediciones de la prueba TBA, aunque con una ligera excepción para el caso de la muestra de control. De nuevo, los valores obtenidos para el caso de las mediciones son menores en relación con el caso de los controles).

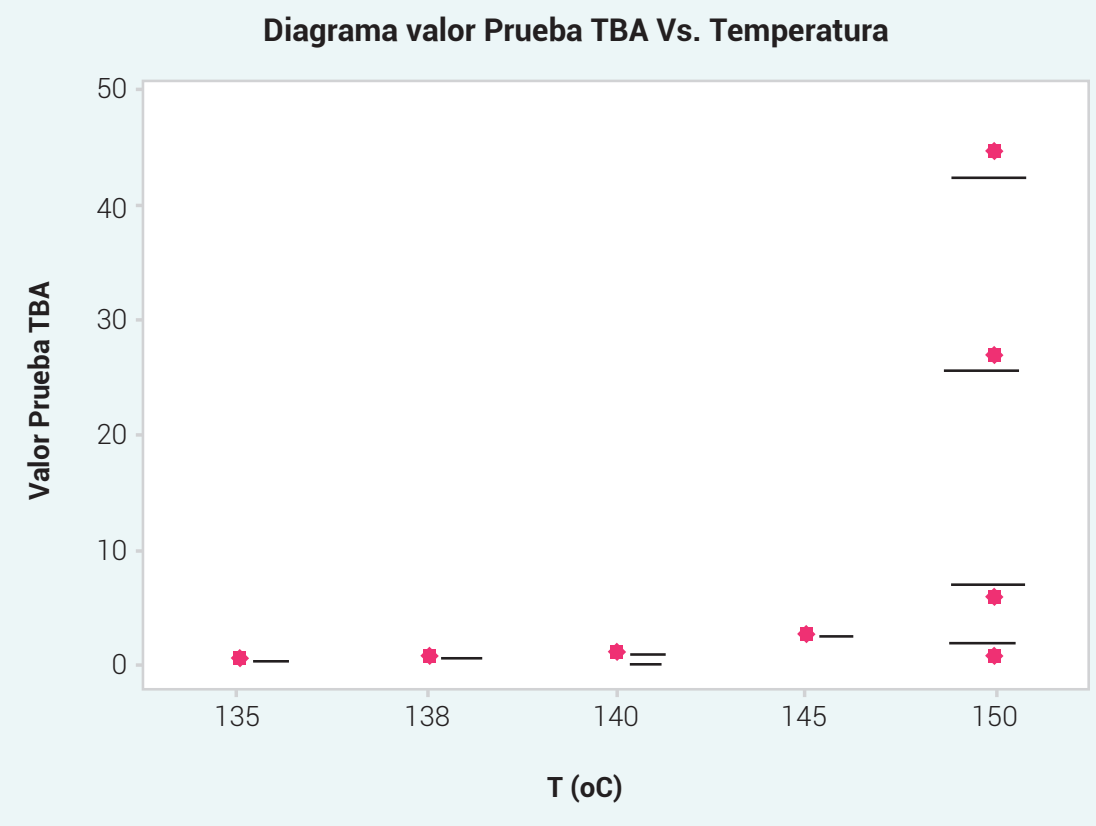

Figura 25. Diagrama valor prueba TBA vs. temperatura Fuente: sPSS, versión 13.

En este gráfico, se observa que prácticamente todas las observaciones para el valor de la prueba TBA son mayores para el caso de aquellos controles recalentados a una temperatura de $150{ }^{\circ} \mathrm{C}$, en comparación con las mediciones para cada uno de los establecimientos que muestran valores claramente menores.

Convenciones:

- Papitodo: A

- Rincón Gourmet: B

- Paola: C

- Pollo Loco: D

- Integrales: E 


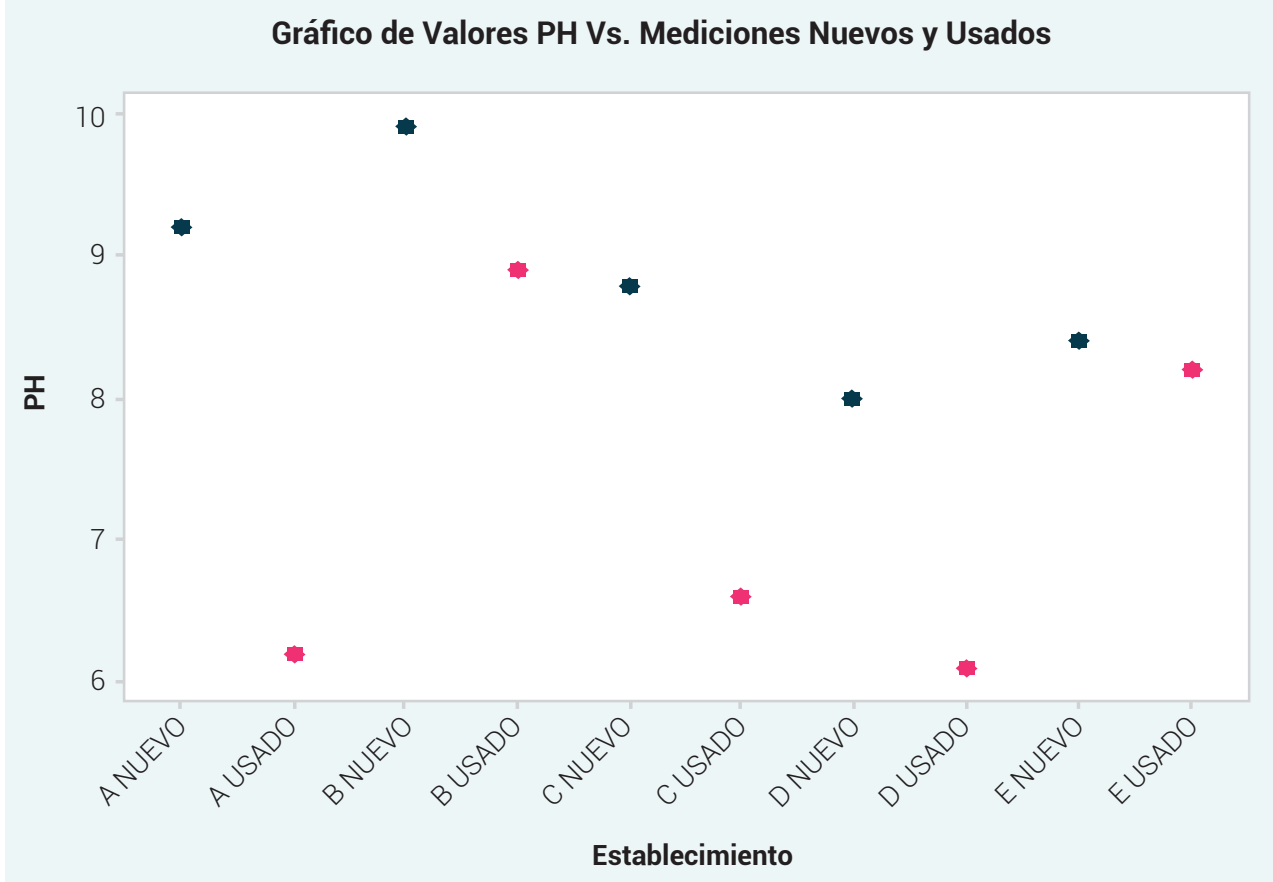

Figura 26. Valores $\mathrm{pH}$ vs. mediciones nuevos y usados Fuente: SPSS, versión 13.

Existe una ligera tendencia a obtener mayores valores en las mediciones del pH para el caso de los aceites nuevos empleados en cada uno de los establecimientos. También, es importante notar que en ningún caso las mediciones de pH para los aceites nuevos son menores a los valores para los aceites usados.

\section{DISCUSIÓN}

La importancia del presente trabajo consistió en determinar la presencia de malonaldehído en aceites recalentados en diferentes cafeterías de la universidad y en réplicas obtenidas en el laboratorio. Se hizo a partir de una sustancia química llamada ácido tiobarbitúrico (TBA) mediante el espectrofotómetro de luz visible a una longitud de onda de $540 \mathrm{~nm}$, en un procedimiento de tres fases, tomando en cuenta además parámetros de identificación como la temperatura, el color y el pH.

Respecto a los resultados obtenidos, se demuestra que existe malonaldehído en las muestras tomadas en las cafeterías y en las réplicas de laboratorio, lo que genera una relación directa entre los valores de absorbancia de las diferentes muestras y la prueba de TBA. 
Por otro lado, se obtuvieron los colores amarillo intenso y anaranjado en el $100 \%$ de las muestras de aceites usados en las cafeterías y en el $75 \%$ de las réplicas obtenidas en el laboratorio. Esta característica es un indicador cualitativo de la presencia de malonaldehído en las muestras analizadas y consideradas como positivas para este estudio.

De igual forma, pudimos observar que el pH descendió en el $100 \%$ de las muestras usadas tomadas en las cafeterías del campus, en tanto que en el $60 \%$ de las réplicas desarrolladas en el laboratorio los valores de $\mathrm{pH}$ tuvieron un comportamiento similar con una disminución en la escala, siendo este hecho indicativo de un proceso de degradación del aceite.

A su vez, valores de temperatura por encima de $130^{\circ} \mathrm{C}$ están relacionados con los resultados obtenidos en los valores de TBA considerados como positivos, lo cual corrobora que existe un proceso de degradación. También, se evidencia una clara diferencia entre las muestras tomadas en las cafeterías de aceites nuevos y usados. En el primer caso, los valores para TBA están por debajo de 0,05, mientras que en los aceites sometidos a calentamiento (usados) estos valores están por encima de 0,05.

En otros estudios realizados, se han obtenido resultados similares; por ejemplo, se puede establecer que el análisis estadístico de los resultados obtenidos en el trabajo de Rojas y Narváez ${ }^{10}$ demostró que solamente los efectos del tiempo y la temperatura son estadísticamente significativos con el $95 \%$ de nivel de confianza $(p<0,05)$, y que el incremento en el valor de estas variables aumenta considerablemente el deterioro del aceite ${ }^{11}$.

El estudio de Gutiérrez De la Cruz y Ruber ${ }^{12}$ menciona la presencia de color amarillo ámbar y pardo rojizo en el $88 \%$ de las muestras de aceites sometidas a temperaturas de frituras, siendo esta coloración un indicativo de que se encuentran en etapa de alteración, pues el oscurecimiento del color es directamente proporcional al tiempo de utilización del aceite en la fritura ${ }^{13}$.

En un estudio realizado por Pérez et al., se muestran los efectos desfavorables de la temperatura en atmosfera de oxígeno sobre la estabilidad térmica de los

10 Efraín Hisnardo Rojas Uribe y Paulo César Narváez Rincón. Método de análisis de calidad del aceite freído por inmersión para pequeñas y medianas empresas. INGENIERÍA E INVESTIGACIón 1. Abril de 2011. Pág. 83-91.

11 Ibid.

12 Huamán Gutiérrez, Juan Orlando De la Cruz Rodríguez y Eduard Ruber. FORMACIÓN DE HIDROCARBUROS AROMÁTICOS POLICÍCLICOS Y DEL 3, 4 BENZOPIRENO EN ACEITES COMESTIBLES ALTERADOS POR RECALENTAMIENTO. Editorial Universidad Mayor de San Marcos. (2002).

13 Rojas y Narváez, supra, nota 13. 
aceites $^{14}$. De otro lado, el estudio de Sjaastad y Svendsen ${ }^{15}$ demostró que durante procedimientos de fritura con diferentes clases de aceites fue posible detectar aldehídos en todas las muestras y aldehídos mutagénicos en casi todas las muestras analizadas.

Los parámetros evaluados de pH, color, temperatura y formación de TBA permitieron confirmar el cambio en las cualidades de los aceites analizados y la presencia de malonaldehído en las muestras recolectadas en las cafeterías y en las réplicas obtenidas en el laboratorio. Lo anterior evidencia que ciertos procedimientos utilizados en la preparación de alimentos en algunas cafeterías del campus universitario están generando sustancias tóxicas para la salud de la comunidad educativa. Teniendo en cuenta esta situación y buscando generar cambios actitudinales, se hace necesario informar a la población que trabaja en las cafeterías del campus respecto a esta problemática y proponer la estrategia educativa.

La educación para la salud tiene como finalidad la mejora cualitativa de la vida humana, por lo cual manifiesta un sentido positivo de ayuda y potenciación de la persona para la gestión de su propia salud, promoviendo los cambios ambientales adecuados y el desarrollo de comportamientos que llevan hacia formas de vida más saludables ${ }^{16}$

La sociedad en la que vivimos va evolucionando. Aunque a principios del siglo pasado no se pensaba en la calidad ni en la seguridad de los alimentos, sino más bien en su disponibilidad y cantidad, ya que estos eran escasos y la prioridad era conseguirlos, actualmente la situación ha cambiado de manera notable, pues disponer de alimentos ya no es una limitación y lo que preocupa es lo que comemos. Ahora hablamos de calidad y de seguridad alimentaria ${ }^{17}$.

Por tanto, consideramos importante hacer una intervención en la comunidad educativa que permita adquirir nuevos hábitos de alimentación a través de la educación ambiental, lo cual se logra con procesos de sensibilización y capacitación tanto a productores como a consumidores de la Universidad Santiago de Cali.

14 Isabel Paz Antolín y Mariano Molero Meneses. Aplicación de la espectrofotometría UV-visible al estudio dela estabilidad térmica de aceites vegetales comestibles. GRASAS Y ACEITES 6. 2000. Pág. 424-428. Disponible en https://dialnet.unirioja.es/servlet/articulo?codigo $=2513834$

15 Ann Kristin Sjaastad y Kristin Svendsen. Exposure to mutagenic aldehydes and particulate matter during panfrying of beefsteak with margarine, rapeseed oil, olive oil or soybean oil. ANNALS OF OcCUPATIONAL HYGIENE 8. Noviembre de 2008. Pág. 739-745. Disponible en https://doi.org/10.1093/annhyg/men060.

16 Rogelio Perea Quesada. EdUCACIón PARA LA SALUd DE NUESTRO TIEMPo. Editorial Díaz de Santos. (2004).

17 Pilar Vaquero. GENÉTICA, NUTRICIÓN Y ENFERMEDADES. Editorial Edimsa. (2008). 
En el desarrollo de este trabajo, se logró determinar la presencia de malonaldehído en los aceites recalentados tomados como muestra de las diferentes cafeterías evaluadas de la Universidad Santiago de Cali a través de la técnica del TBA. En las réplicas experimentales también se pudo evidenciar esta sustancia química, lo que conduce a una confirmación de que los aceites sometidos a calentamiento a temperaturas mayores a $1000^{\circ} \mathrm{C}$ sufren un proceso de oxidación que ocasiona el rompimiento de las grasas y genera un nuevo compuesto que constituye un aldehído.

Tanto en las muestras de las cafeterías como en las réplicas se observa claramente la relación directa entre el valor de la prueba TBA y las variables color, pH y temperatura. La presencia de malonaldehído en los aceites recalentados cuando son usados en la preparación de alimentos genera sustancias tóxicas que afectan la salud de las personas.

La educación ambiental tiene como principio promover la sensibilización ante la problemática de contaminación buscando generar cambios hacia una conciencia cultural y conductual que propendan a favorecer a los seres vivos y a orientar las acciones al desarrollo sostenible. Así mismo, tiene en cuenta las dinámicas sociales, culturales y económicas que conforman la vida de una comunidad. Los modelos de consumo tienen un impacto directo sobre los ecosistemas y son uno de los pilares a modificar para alcanzar el desarrollo sostenible, de tal forma que la alimentación es uno de los principales factores que permite establecer el más alto nivel sostenible de salud y bienestar en una comunidad.

Todos los seres humanos debemos responsabilizarnos de contribuir a la protección del ambiente como herramienta para aportar a la salud individual y colectiva. Por tanto, los resultados del presente trabajo serán informados a la Directiva General de la universidad con el objetivo de que se establezcan medidas que estén articuladas con la política de universidad saludable.

\section{REFERENCIAS}

Alberto Vega Turizo. GUÍA PARA LA ELABORACIÓN DE ACEITES COMESTIBLES, CARACTERIZACIÓN Y PROCESAMiento de nUeCES. Convenio Andrés Bello. (2004).

Ann Kristin Sjaastad y Kristin Svendsen. Exposure to mutagenic aldehydes and particulate matter during panfrying of beefsteak with margarine, rapeseed oil, olive oil or soybean oil. ANNALS of Occupational Hygiene 8. Noviembre de 2008. Pág. 739-745. Disponible en https://doi. org/10.1093/annhyg/men060. 
Corte Constitucional de Colombia. SentenciA T-204 de 2004. (M.P. Clara Inés Vargas Hernández; marzo 4 de2004). Disponibleen https://www.corteconstitucional.gov.co/relatoria/2004/T-204-04. htm

Corte Constitucional de Colombia. Sentencia T-029 de 2014. (M.P. Jorge Ignacio Pretelt Chaljub; enero 27 de 2014). Disponible en https://www.corteconstitucional.gov.co/relato$\mathrm{ria} / 2014 / \mathrm{T}-029-14 . \mathrm{htm}$

Corte Constitucional de Colombia. SentencIA C-032 de 2019. (M.P. Gloria Stella Ortiz Delgado; enero 30 de 2019). Disponible en https://www.corteconstitucional.gov.co/relatoria/2019/C-032-19. $\mathrm{htm}$

Corte Constitucional de Colombia. Sentencia T-260 de 2019. (M.P. Antonio José Lizarazo Ocampo; junio 6 de 2019). Disponible en https://www.corteconstitucional.gov.co/relato$\mathrm{ria} / 2019 / \mathrm{T}-260-19 . \mathrm{htm}$

Denier Palacios Mena y Maryuri Moreno Rodallega. Medidas de mitigación y corrección que utiliza el Estado para subsanar los daños producidos por los entables mineros en el barrio El Oasis del municipio de Certegui, departamento de Chocó. DIXI 30. 2019. Pág. 1-28. Disponible en https:// repository.ucc.edu.co/handle/20.500.12494/17025

Efraín Hisnardo Rojas Uribe y Paulo César Narváez Rincón. Método de análisis de calidad del aceite freído por inmersión para pequeñas y medianas empresas. INGENIERÍA E INVESTIGACIÓN 1. Abril de 2011. Pág. 83-91.

Fernelly Varón-Martínez. El fenómeno de la deserción escolaren un contexto local: estudio de la política municipal. DIXI 26. Agosto de 2017. Disponible en https://doi.org/10.16925/di.v19i26.1953

Francisco Javier Rivera Olarte. Breve estudio descriptivo del fenómeno ambiental en sus dos dimensiones: daño ambiental y daño ecológico. DIXI 25. 2017. Pág. 83-104. Disponible en https:// dialnet.unirioja.es/servlet/articulo?codigo=6794852

Huamán Gutiérrez, Juan Orlando De la Cruz Rodríguez y Eduard Ruber. FoRMACIÓN DE HIDROCARBUROS AROMÁTICOS POLICÍCLICOS Y DEL 3, 4 BENZOPIRENO EN ACEITES COMESTIBLES ALTERADOS POR RECALENTAMIENTO. Editorial Universidad Mayor de San Marcos. (2002).

Isabel Paz Antolín y Mariano Molero Meneses. Aplicación de la espectrofotometría uv-visible al estudio dela estabilidad térmica de aceites vegetales comestibles. GRASAS y ACEITES 6. 2000. Pág. 424-428. Disponible en https://dialnet.unirioja.es/servlet/articulo?codigo=2513834 
Nayibe Bonilla Mosquera, María Fernanda Pérez Garzón, Juan Carlos Millán Estupiñán 35 Jairo Puentes Brugés. Venenos En EL HOGAR. Ediciones USTA. (2006).

Pilar Vaquero. GENÉTICA, NUTRICIÓN Y ENFERMEDADES. Editorial Edimsa. (2008).

Rogelio Perea Quesada. Educación PARA LA SALUd DE NUESTRO TIEMPo. Editorial Díaz de Santos. (2004). 